\title{
Noise-Induced Dysregulation of Quaking RNA Binding Proteins Contributes to Auditory Nerve Demyelination and Hearing Loss
}

\author{
Clarisse H. Panganiban, ${ }^{1 *} \oplus$ Jeremy L. Barth, ${ }^{2 \star}$ Lama Darbelli, ${ }^{3 *}$ ๑ Yazhi Xing, ${ }^{1,4}$ Jianning Zhang, ${ }^{1}$ Hui Li, ${ }^{1}$ \\ Kenyaria V. Noble, ${ }^{1}$ Ting Liu, ${ }^{1}$ LaShardai N. Brown, ${ }^{1}$ Bradley A. Schulte, ${ }^{1}$ Stéphane Richard, ${ }^{3}$ and $\odot$ Hainan Lang ${ }^{1}$ \\ Departments of ${ }^{1}$ Pathology and Laboratory Medicine, ${ }^{2}$ Regenerative Medicine, Medical University of South Carolina, Charleston, South Carolina 29425, \\ ${ }^{3}$ Terry Fox Molecular Oncology Group and the Bloomfield Center for Research on Aging, Lady Davis Institute for Medical Research, Sir Mortimer B. Davis \\ Jewish General Hospital, Departments of Oncology and Medicine, Montréal, Québec H3T 1E2, Canada, and ${ }^{4}$ Shanghai Jiao Tong University Affiliated \\ Shanghai Sixth's People's Hospital, Shanghai 200233, People's Republic of China
}

Noise exposure causes auditory nerve (AN) degeneration and hearing deficiency, though the proximal biological consequences are not entirely understood. Most AN fibers and spiral ganglion neurons are ensheathed by myelinating glia that provide insulation and ensure rapid transmission of nerve impulses from the cochlea to the brain. Here we show that noise exposure administered to mice of either sex rapidly affects myelinating glial cells, causing molecular and cellular consequences that precede nerve degeneration. This response is characterized by demyelination, inflammation, and widespread expression changes in myelin-related genes, including the RNA splicing regulator Quaking $(\mathrm{QKI})$ and numerous $\mathrm{QKI}$ target genes. Analysis of mice deficient in $\mathrm{QKI}$ revealed that $\mathrm{QKI}$ production in cochlear glial cells is essential for proper myelination of spiral ganglion neurons and AN fibers, and for normal hearing. Our findings implicate QKI dysregulation as a critical early component in the noise response, influencing cochlear glia function that leads to AN demyelination and, ultimately, to hearing deficiency.

Key words: auditory glia; dysmyelination; glial dysfunction; noise exposure; quaking; sensorineural hearing loss

Significance Statement

Auditory glia cells ensheath a majority of spiral ganglion neurons with myelin, protect auditory neurons, and allow for fast conduction of electrical impulses along the auditory nerve. Here we show that noise exposure causes glial dysfunction leading to myelin abnormality and altered expression of numerous genes in the auditory nerve, including QKI, a gene implicated in regulating myelination. Study of a conditional mouse model that specifically depleted QKI in glia showed that QKI deficiency alone was sufficient to elicit myelin-related abnormality and auditory functional declines. These results establish QKI as a key molecular target in the noise response and a causative agent in hearing loss.

\section{Introduction}

Extrinsic factors, such as exposure to noise and ototoxic drugs, as well as intrinsic genetic defects and aging, cause the degeneration

\footnotetext{
Received Aug. 29, 2017; revised Jan. 22, 2018; accepted Jan. 29, 2018.

Author contributions: C.H.P., J.L.B., L.D., and H. Lang designed research; C.H.P., J.L.B., L.D., Y.X., J.Z., H. Li, and H. Lang performed research; S.R. contributed unpublished reagents/analytic tools; C.H.P., J.L.B., Y.X., K.V.N., T.L., L.N.B., B.A.S., and H. Lang analyzed data; C.H.P., J.L.B., and H. Lang wrote the paper.

This work has been supported by National Institutes of Health Grants R01-DC-012058 (H.L.), P50-DC-00422 (H.L.), R25-GM-072643 (C.H.P., K.V.N., L.N.B.), F31-DC-015741 (L.N.B.), T32-DC-014435 (K.V.N., L.N.B.), P30-GM103342 (J.L.B.), P20-GM-103499 (J.L.B.), P30-CA-138313, and S10-0D-018113 from the Cell \& Molecular Imaging Shared Resource Center, Hollings Cancer Center; Grant C06-RR-014516 from the Extramural Research Facilities Program of the National Center for Research Resources; and the Medical University of South Carolina Office of the Vice President for Research. We thank Juhong Zhu, Nancy Smythe, Reycel Rodriguez, and Linda McCarson for their technical assistance.

${ }^{*}$ C.H.P., J.L.B., and L.D. contributed equally to this work.
}

of spiral ganglion neurons (SGNs) and auditory nerve (AN) fibers, resulting in hearing loss (Liberman and Kiang, 1978; Spoendlin, 1984; Zimmermann et al., 1995; Bao and Ohlemiller, 2010). Approximately 95\% of AN fibers are myelinated by cochlear glia. Myelinating glia regulate the assembly of cellular adhesion molecules and ion channels that are key elements of axo-glial junctions and the paranodal structures at the node of Ranvier, a

The authors declare no competing financial interests.

Correspondence should be addressed to either of the following: Dr. Hainan Lang, Department of Pathology and Laboratory Medicine, Medical University of South Carolina, 165 Ashley Avenue, P.0. Box 250908, Charleston, SC 29425, E-mail: langh@musc.edu; or Dr. Jeremy L. Barth, Department of Regenerative Medicine, Medical University of South Carolina, 173 Ashley Avenue, Charleston, SC 29425, E-mail: barthj@musc.edu.

DOI:10.1523/JNEUROSCI.2487-17.2018

Copyright $\odot 2018$ the authors $\quad 0270-6474 / 18 / 382551-18 \$ 15.00 / 0$ 
critical structure for saltatory conduction (Susuki, 2013). Cochlear glia-associated paranodal structures and nodal clusters of $\mathrm{Na}^{+}$channels are present along the entire length of AN processes (Hossain et al., 2005; Kim and Rutherford, 2016). In the brain, dynamic regulation of nerve myelination, required for nerve plasticity and repair, continues into adulthood (Long and Corfas, 2014; Rao and Pearse, 2016). Myelin deficiencies significantly deplete AN activity (Zhou et al., 1995; El-Badry et al., 2007; Jyothi et al., 2010; Akil et al., 2015). A recent study in mice showed that the induction of glial loss elicited remyelination but disrupted the paranodal structure at the first heminodes, causing hearing deficiency (Wan and Corfas, 2017). Using a rat model, Tagoe et al. (2014) reported that noise exposure induced pathologies of paranodal axo-glial junctions and decreased conduction velocity in the central processes of the AN projecting from SGNs to brainstem.

RNA binding proteins (RBPs) control post-transcriptional events such as pre-mRNA splicing and mRNA stability, localization, and translation (Fu and Ares, 2014). This wide range of function allows these proteins to modulate the proteome of neural progenitor cells needed to facilitate differentiation into glial and neuronal cells and to conduct myelination and form neural circuitry (Wu et al., 2002). The Quaking (QKI) gene encodes a $\mathrm{KH}$-type family of RBPs and generates three major spliced transcripts encoding QKI-5, QKI-6, and QKI-7 isoforms that differ in their C termini (Ebersole et al., 1996; Hardy et al., 1996). QKI-5 harbors a nuclear localization signal and is located in the nucleus, while QKI-6 is expressed throughout the cell and QKI-7 is cytoplasmic (Pilotte et al., 2001; Wu et al., 2002). QKI-5 and QKI-6 directly or indirectly regulate myelin-specific genes such as myelinassociated glycoprotein (Zhao et al., 2006, 2010; Mandler et al., 2014).

Here we have examined the linkage between noise exposure and demyelination of SGNs and peripheral processes, focusing on the molecular mechanisms that drive myelinating glial dysfunction. For this purpose, we used a noise exposure paradigm in mice that resulted in permanent hearing loss. Our data show that noise exposure causes demyelination of SGNs and disruption of paranodal axo-glial junctions, promoting demyelination-associated inflammatory responses and widespread changes in myelinrelated gene expression in the AN. Noise exposure caused a rapid response in QKI RBP expression that was accompanied by changes in the expression of numerous QKI targets associated with myelination. Similar investigation of postnatal AN development revealed that the upregulation of QKI-6 and QKI-7 and the downregulation of QKI-5 occurred around the first 2 weeks after birth, coinciding with myelination. Targeted deficiency of QKI in adult cochlear glia disrupted myelin structure and paranodal axo-glial junctions and resulted in hearing loss. Together, these results identify QKI dysregulation as a critical early component in the noise response, leading to glia dysfunction, demyelination, and hearing loss.

\section{Materials and Methods}

Animals. All aspects of animal research were conducted in accordance with the guidelines of the Institutional Animal Care and Use Committee of the Medical University of South Carolina (MUSC) for CBA/CaJ mice and with the McGill University guidelines set by the Canadian Council on Animal Care for the QKI $I^{F L / F L ; P L P C r e E R T}$ and $Q K I^{F L / F L ;-}$ mice. CBA/CaJ mice, originally purchased from The Jackson Laboratory, were bred in a low-noise environment at the Animal Research Facility at MUSC. The Quaking Cre-inducible knock-out mouse model QKI $I^{F L / F L ; P L P C r e E R T}$ and littermate control QKI ${ }^{F L / F L ;-}$ were housed in a similar environment at the Lady Davis Institute for Medical Research Small Animal Research Core. All mice received food and water ad libitum and were maintained on a
$12 \mathrm{~h}$ light/dark cycle. Subjects with signs of external ear canal and middle ear obstruction or middle ear infection were excluded. Aside from the exclusion criteria, subjects were chosen for their experimental groups at random. Young-adult $\mathrm{CBA} / \mathrm{CaJ}$ mice aged $6-15$ weeks and postnatal mice at ages postnatal day $0(\mathrm{P} 0), \mathrm{P} 3, \mathrm{P} 7, \mathrm{P} 10, \mathrm{P} 14$, and $\mathrm{P} 21$ were used for this project. The $Q K I^{F L / F L ; P L P C r e E R T}$ model (Darbelli et al., 2016) was produced by crossing the $Q K I^{F L / F L}$ mouse, which has loxP sites flanking exon 2 of Quaking, with PLP-CreERT mice (Doerflinger et al., 2003). The knockout was induced in $\sim 10$-week-old $Q K I^{F L / F L ; P L P C r e E R T ~}$ mice by five intraperitoneal injections of $10 \mathrm{mg} / \mathrm{ml}$ 4-hydroxytamoxifen (OHT) at 1 $\mathrm{mg} / 25 \mathrm{~g}$ once per day. The knockout of exon 2 , which is common for the three major QKI isoforms QKI-5, QKI-6, and QKI-7, should result in a null allele (Darbelli et al., 2016). Experiments were performed on $\sim 15$ week-old $Q K I^{F L / F L ; P L P C r e E R T}$ mice $28 \mathrm{~d}$ after the final OHT injection. Age-matched $Q K I^{F L / F L ;-~}$ littermates were used as controls.

Experimental design and statistical analyses. Statistical analyses were completed using either dChip (Li and Wong, 2001; RRID:SCR_013504), Microsoft Excel or GraphPad Prism 7 (GraphPad Software; RRID: SCR_002798). Mice of either sex were used throughout the studies, as our analysis showed that there was no significant difference in the effects from noise exposure between sexes (data not shown). Mice used in each experiment were assigned identification numbers to blind investigators during data analyses. Sample sizes for auditory brainstem response (ABR) threshold measurements were estimated using the $\mathrm{R}$ package "pwr" (Champely, 2017). Sample sizes for other physiological measurements (e.g., amplitude and latency), quantitative PCR (qPCR) studies, and ultrastructural observations of type I SGNs (e.g., compactness of myelin and $G$ ratio measurements) were based on prior studies (Xing et al., 2012; Lang et al., 2015). For microarray studies, prior analyses of injured mouse auditory nerve demonstrated that a sample size of $n=3$ was sufficient for robust detection of differentially expressed genes while maintaining acceptable (i.e., moderate to low) false discovery rates (Lang et al., 2015). Unless otherwise stated, each immunostaining experiment used three mice for each experimental group. Representative images from each immunostaining experiment are shown in the figures. Exact sample sizes for all other experimental procedures are indicated in Table 1. Data in the figures are presented as either the mean $\pm \mathrm{SE}$ or the mean $\pm \mathrm{SD}$, as noted. Data were tested for normal distribution using the Shapiro-Wilk normality test, and the groups being compared were found to have similar variances. Depending on distribution, and data for thresholds, amplitudes, and latencies were analyzed using either the nonparametric Mann-Whitney test or Student's $t$ test, unpaired and two tailed. Analysis of relative mRNA values obtained by qPCR for developmental time points was performed by one-way ANOVA with Bonferroni's post-test; analysis of qPCR values for noise-injured samples versus controls was performed by Student's $t$ test, unpaired and two tailed. G ratio values compared with axon diameter or myelin thickness values were plotted with computed linear regression lines. A $p$ value of $\leq 0.05$ was considered statistically significant.

Noise exposure. Noise exposure procedures were modified from previous studies (Lang et al., 2006). Briefly, young adult CBA/CaJ mice were exposed to $8-16 \mathrm{kHz}$ octave-band noise at a 100,106 , or $112 \mathrm{~dB}$ SPL for $2 \mathrm{~h}$ using a Beyer DT48 Drive (Beyerdynamic) and monitored with a probe-tube microphone ( $\mathrm{B} \& \mathrm{~K} 4134$, Brüel \& Kjær). Mice were then killed immediately (Im), or on day 1, 7, 14, or 30 after noise exposure.

Physiological procedures. For each auditory function measurement, animals were anesthetized via an intraperitoneal injection of a cocktail of 20 $\mathrm{mg} / \mathrm{kg}$ xylazine and $100 \mathrm{mg} / \mathrm{kg}$ ketamine, and testing was performed in a sound isolation booth (at MUSC) or a portable sound isolation apparatus (Lady Davis Institute for Medical Research). Each piece of auditory brainstem measurement equipment was professionally calibrated before use, and sound stimuli were delivered into the ear canal via a $10-\mathrm{mm}$ long, 3- to 5-mm-diameter tube. ABR values acquired via Tucker Davis Technologies Lab Rat Neurophysiology System 3 (RRID:SCR_006495) and processed via the SigGen software package (version 4.4.1) were measured as previously described (Lang et al., 2015). Briefly, for young-adult $\mathrm{CBA} / \mathrm{CaJ}$ mice, $\mathrm{ABRs}$ were evoked at frequencies 4, 5.6, 11.3, 16, 22.6, 32, 40 , and $45.2 \mathrm{kHz}$ with $5 \mathrm{~ms}$ tone pips with $\cos ^{2}$ rise/fall times of $0.5 \mathrm{~ms}$ delivered 31 times/s. Sound levels were reduced in $5 \mathrm{~dB}$ steps, from 90 to 
Table 1. Sample sizes for each experimental procedure

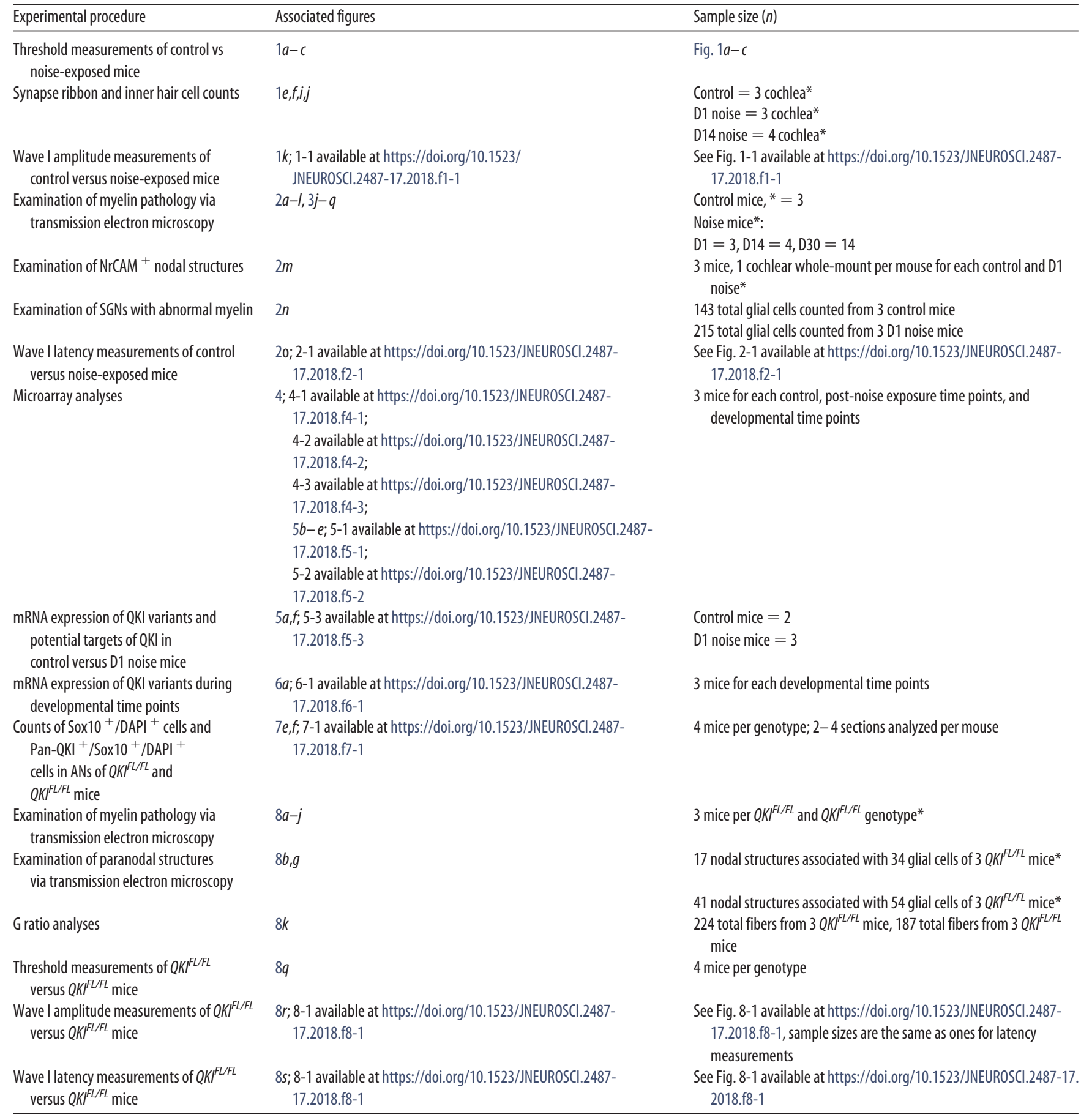

D, Day; $n$, number of mice.

*Representative images are shown in the figures.

$10 \mathrm{~dB}$ SPL. Results for each mouse were analyzed for threshold and suprathreshold peak amplitudes and onset latencies at each frequency. For noise-exposed mice, ABRs were recorded prenoise and postnoise Im, or on days $1,3,7,14$, and/or 30, depending on the designated end point of each group. For each noise and control group, thresholds were averaged at each frequency, and mean \pm SEM values were calculated and plotted using Origin 6.0 software (OriginLab; RRID:SCR_002815). For suprathreshold amplitude and onset latency, measurements for no-noise control and day 3 postnoise groups were averaged at each intensity level for each frequency.

ABRs for mutant $Q K I^{F L / F L ; P L P C r e E R T}$ and $Q K I^{F L / F L ;-}$ littermate controls were recorded at $\sim 15$ weeks of age, just before sample collection. Record- ings were performed and collected from the right ears of each mouse using a portable SmartEP system and software (version 3.97; Intelligent Hearing Systems). ABRs were evoked at frequencies of 8 and $16 \mathrm{kHz}$ with $1 \mathrm{~ms}$ duration Blackman tones delivered at 19.3 times/s. Sound levels were reduced in $10 \mathrm{~dB}$ steps from 100 to $10 \mathrm{~dB}$ SPL. Threshold measurements for each group were plotted by mean \pm SEM values for each frequency. ABR wave I amplitudes and latencies were plotted by mean \pm SEM values for each intensity level per frequency.

Cochlear nerve tissue collection and total RNA isolation. Cochleae from noise-exposed, controls and postnatal CBA/CaJ mice were collected at their designated end points. Microdissections were performed to isolate the AN from the rest of the cochlear structures, taking care to preserve 
peripheral fibers. Two cochleae from each mouse were pooled for individual samples. Total RNA was purified from each sample using the miRNeasy Mini Kit (Qiagen) per manufacturer instructions. The quality of each total RNA isolation was assessed using the Agilent 2100 Bioanalyzer System, and low-quality samples showing degradation or contamination were excluded.

Microarray hybridization and data analysis. Procedures for probe preparation, hybridization, and microarray data processing were modified from those described previously (Allen et al., 2009). Noise-exposed AN samples were collected Im, and on days 1, 7, and 14 after exposure. Total RNA (50 ng) was converted into biotin-labeled cRNA using the 3' IVT Express Kit (Affymetrix). Hybridization to Mouse 4302.0 GeneChips (Affymetrix), and posthybridization washing, staining, and fluorescence scanning were conducted using Affymetrix instrumentation following manufacturer recommendations. Normalized hybridization data were obtained by robust multiarray average (Irizarry et al., 2003), and detection calls were obtained by MAS 5.0 using Expression Console software (Affymetrix). Microarray data are deposited in NCBI Gene Expression Omnibus (accession GSE100365; RRID:SCR_007303). Comparative analyses were conducted with dChip software. Given that samples had been prepared from mice of both sexes (nine females, six males), a preliminary analysis of expression data was conducted comparing females with males. This analysis included a separate set of microarray expression data generated for lateral wall of the same animals. Comparison based solely on tissue and sex identified 48 genes that were significantly different between male and female in both AN and cochlear lateral wall ( $p<$ 0.01 , Student's $t$ test, unpaired, two tailed, not assuming equal variance). Review of these genes confirmed that many were X- or Y-linked. These sex-dependent genes were eliminated from the AN dataset for all subsequent analyses [Fig. 4-2 available at https://doi.org/10.1523/JNEUROSCI.248717.2018.f4-2 (extended datasets were labeled as Figure X-Y, with "X" indicating the main figure and " $Y$ " indicating the extended data)]. For unbiased expression analysis of the effect of noise, significant difference was defined as an absolute fold change of $>1.5$ and $p<0.05$ (Student's $t$ test, unpaired, two tailed) for at least one pairwise relationship among the control and postnoise time points; the false discovery rate, estimated based on iterative comparisons using permuted group assignments, was $\sim 24 \%$. Enrichment analysis of biological process terms was conducted with DAVID (Database for Annotation, Visualization, and Integrated Discovery; Huang et al., 2009a, 2009b; RRID:SCR_001881) using mouse gene symbols as input. Significantly enriched biological processes (adjusted $p<0.05$, Benjamini-Hochberg adjustment) were summarized with REVIGO (Supek et al., 2011; RRID:SCR_005825). A set of myelinrelated genes was compiled from several resources: (1) mRNAs enriched in myelinating oligodendrocytes in mouse cerebral cortex compared with astrocytes, neurons, oligodendrocyte progenitor cells, newly formed oligodendrocytes, microglia, and endothelia at FPKM (fragments per kilobase of transcript per million mapped reads) thresholds of $0.1,1,10$, and 20 (Zhang et al., 2014); (2) mRNAs with normalized read counts of $>100$ and more than twofold increase in male mouse brain myelin (Thakurela et al., 2016); (3) genes on the mouse 4302.0 GeneChip (Affymetrix) identified by query for the term "myelin"; and (4) a curated set of genes related to the node of Ranvier. A set of putative QKI target genes was compiled from genes alternatively spliced in a model of QKI deficiency (Darbelli et al., 2016) and genes containing a QKI response element (QRE; Galarneau and Richard, 2005). Gene sets were processed with the NetAffx webtool (Affymetrix; RRID:SCR_007817) to match genes with corresponding microarray content. Differential expression for focused analysis of myelin-related and putative QKI target gene sets was defined as $p<0.05$ (Student's $t$ test, unpaired, two tailed) for at least one pairwise relationship among the control and postnoise time points.

Quantitative PCR. Reverse transcription of total RNA was performed with the iScript cDNA synthesis kit (BIO-RAD) using 25-50 ng of total RNA in $20 \mu \mathrm{l}$ reaction volumes according to manufacturer protocols. The resulting cDNA samples were diluted to $100 \mu \mathrm{l}$ by the addition of water. qPCR was conducted as previously described (Cooley et al., 2014) with a CFX96 Touch Real-Time PCR Detection System (BIO-RAD) using SsoAdvanced Universal SYBR Green Supermix (BIO-RAD). Briefly, amplifications were performed in $10 \mu \mathrm{l}$ reaction volumes with $2 \mu \mathrm{l}$ of
Table 2. Primer sequences used for quantitative PCR

\begin{tabular}{|c|c|c|}
\hline Gene symbol & Direction & PCR primer sequence $\left(5^{\prime}\right.$ to $\left.3^{\prime}\right)$ \\
\hline \multirow[t]{2}{*}{$C d c 42$} & Forward & TGGAGAGCCATACACTCTTGG \\
\hline & Reverse & TCTGTCTGTGGATAACTTAGCG \\
\hline \multirow[t]{2}{*}{ Gal3st1 } & Forward & ATTGCTGCTGTACTCCTATGTGG \\
\hline & Reverse & CCACTGGCTCATTGGGAATAGGG \\
\hline \multirow[t]{2}{*}{$\operatorname{lrgm} 1$} & Forward & CCTAGGAAGAAAGGGGTGACG \\
\hline & Reverse & GAGTTGGTTCCTTCGAATGCC \\
\hline \multirow[t]{2}{*}{ Rap1gds1 } & Forward & GTGCCCTCAGGAATCTAGCC \\
\hline & Reverse & AAAACCGTCTCCGTGACACC \\
\hline \multirow[t]{2}{*}{ Ugt8a } & Forward & TTCATGGGTCCAGCCTATGG \\
\hline & Reverse & САССАCTTACCCACCTCTGC \\
\hline \multirow[t]{2}{*}{$C 1 q b$} & Forward & CAGGCACTCCAGGGATAAAGG \\
\hline & Reverse & ССССТTTCTCTCCAAACTCACC \\
\hline \multirow[t]{2}{*}{$\mathrm{Clqc}$} & Forward & GGAAGGACGGGCATGATGG \\
\hline & Reverse & CGCCCTTCTGACCCTTGG \\
\hline \multirow[t]{2}{*}{ Ifit3 } & Forward & TCTCTCCCTGACTCCTCTGC \\
\hline & Reverse & TCAAAAGGTGCTCTGTCTGC \\
\hline \multirow{2}{*}{$\mathrm{Cd} 12$} & Forward & ACGTCCGGAAGCTGAAGAGC \\
\hline & Reverse & TTGGGGTCAGCACAGATCTCC \\
\hline \multirow[t]{2}{*}{ Pou3f2 } & Forward & TTTCTTCAGATCCCCCAGACC \\
\hline & Reverse & TGCATAAAGCGGGCAAACC \\
\hline \multirow[t]{2}{*}{ Gadd45a } & Forward & AGCTGCTGCTACTGGAGAACG \\
\hline & Reverse & GATCCTTCCATTGTGATGAATGTGG \\
\hline \multirow[t]{2}{*}{ Hprt } & Forward & TCCTCCTCAGACCGCTTTT \\
\hline & Reverse & CCTGGTTCATCATCGCTAATC \\
\hline \multirow[t]{2}{*}{ Tbp } & Forward & TGAGAGCTCTGGAATTGTACCG \\
\hline & Reverse & TGATGACTGCAGCAAATCGC \\
\hline \multirow[t]{2}{*}{ Actb } & Forward & CGCGGCGATATCATCATCC \\
\hline & Reverse & CCTCGCCTTTGCCGATCC \\
\hline
\end{tabular}

diluted cDNA template, $1 \times$ Supermix, and primer concentrations of 0.4 $\mu \mathrm{M}$. All reactions were performed in technical triplicate with 40 cycles of two-step cycling and a concluding melting procedure according to manufacturer recommendations. Experimental and reference gene primers designed for this project are given in Table 2. Other mouse gene primer sets used in the study were total QKI (Pan-QKI; catalog \#QT01058876, Qiagen), QKI-1 (QKI-5; catalog \#MQP073700, GeneCopoeia), QKI-2 (QKI-6; catalog \#MQP073699, GeneCopoeia), and QKI-3 (QKI-7; cata$\log$ \#MQP032742, GeneCopoeia). Melting curve profiles were reviewed to ensure that all amplifications produced single amplicons indicative of reaction specificity. Amplification data were analyzed with the PCR Miner Web tool (Zhao and Fernald, 2005) to calculate reaction efficiencies and cycle thresholds. Relative mRNA expression values for experimental genes were calculated as the starting fluorescence value relative to the geometric mean of starting fluorescence values for two reference genes (Liu and Saint, 2002). Reference genes used in the study were Tbp, Hprt, and Actb.

Immunohistochemistry. Immunohistochemical procedures were modified from previous studies (Lang et al., 2015). After end-point physiological recordings, mouse cochleae were collected and immediately fixed with $4 \%$ paraformaldehyde solution in $1 \times$ PBS for $1-2 \mathrm{~h}$ at room temperature (RT) and decalcified with $0.12 \mathrm{M}$ EDTA at RT for $1-2 \mathrm{~d}$. For mouse cochlear section preparations, the cochleae were embedded in Tissue-Tek OCT compound and sectioned at a thickness of $\sim 10 \mu \mathrm{m}$. For whole-mount preparations of mouse cochlear tissues, the auditory nerves and attached organs of Corti were isolated from the rest of the cochlear structures. The sections of the human temporal bones were obtained from the collections of our previous studies (Xing et al., 2012; Hao et al., 2014). The procedures for human cochlear tissue preparations were reported in detail previously (Xing et al., 2012; Hao et al., 2014).

The primary and secondary antibodies used are listed in Table 3. Staining was performed either indirectly using biotinylated secondaries conjugated with fluorescent avidin (Vector Laboratories) or directly using Alexa Fluor Dyes (Thermo Fisher Scientific). Nuclei were counterstained using propidium iodide (PI), Hoechst stain, or DAPI. Slice and confocal image stacks were collected using a Zeiss LSM 880 NLO microscope with 
Table 3. Primary and secondary antibodies used

\begin{tabular}{|c|c|c|c|c|}
\hline & Host & Company & Catalog no. (RRID no.) & $\overline{\text { Concentration }}$ \\
\hline \multicolumn{5}{|l|}{ Primary antibody } \\
\hline Anti-Cntn1 & Polyclonal goat lgG & R\&D Systems & AF904 (AB_2292070) & $1: 200$ \\
\hline Anti-CtBP2 & Mouse lgG1 & BD Biosciences & 612044 (AB_399431) & $1: 200$ \\
\hline Anti-lba-1 & Rabbit & Wako Pure Chemicals Industries & 019-19741 (AB_839504) & $1: 100$ \\
\hline Anti-Ly6G & Monoclonal rat lgG & Abcam & ab25377 (AB_470492) & $1: 200$ \\
\hline Anti-myosin VIla & Rabbit & Proteus Biosciences & 25-6790 (AB_10015251) & $1: 200$ \\
\hline Anti-neurofilament 200 & Monoclonal mouse lgG1 & Sigma-Aldrich & N0142 (AB_477257) & $1: 200$ \\
\hline Anti-NrCAM & Polyclonal rabbit $\lg G$ & Abcam & $\mathrm{ab} 24344\left(\mathrm{AB} \_448024\right)$ & $1: 200$ \\
\hline Anti-Pan-QKI clone N147/6 & Monoclonal mouse lgG1 & UC Davis/NIH NeuroMab Facility & 75-168 (AB_2173149) & $1: 200$ \\
\hline Anti-PCP-4 & Polyclonal rabbit lgG & Santa Cruz Biotechnology & sc-74816 (AB_2236566) & $1: 200$ \\
\hline Anti-QKI-5 & Polyclonal rabbit lgG & Bethyl Laboratories & A300-183A (AB_2721231) & $1: 200$ \\
\hline Anti-QKI-6 clone N182/17 & Monoclonal mouse lgG1 & UC Davis/NIH NeuroMab Facility & 75-190(AB_10673511) & $1: 100$ \\
\hline Anti-QKI-7 clone N183/15 & Monoclonal mouse lgG1 & UC Davis/NIH NeuroMab Facility & $75-200\left(A B \_10675300\right)$ & $1: 100$ \\
\hline Anti-Sox10 & Polyclonal goat lgG & Santa Cruz Biotechnology & sc-17342 (AB_2195374) & $1: 100$ \\
\hline Anti-Sox2 & Polyclonal Goat lgG & Santa Cruz Biotechnology & SC-17320 (AB_2286684) & $1: 100$ \\
\hline \multicolumn{5}{|l|}{ Secondary antibody } \\
\hline Anti-goat Alexa Fluor 488 & Polyclonal donkey lgG $(\mathrm{H}+\mathrm{L})$ & Thermo Fisher Scientific & A-11055 & $1: 500$ \\
\hline Anti-rabbit Alexa Fluor 568 & Polyclonal donkey lgG $(\mathrm{H}+\mathrm{L})$ & Thermo Fisher Scientific & A-11011 & $1: 500$ \\
\hline Anti-rat Alexa Fluor 488 & Polyclonal donkey $\lg \mathrm{G}(\mathrm{H}+\mathrm{L})$ & Thermo Fisher Scientific & $A-21208$ & $1: 500$ \\
\hline Biotinylated anti-goat lgG & Horse & Vector Laboratories & BA-9500 & $1: 100$ \\
\hline Biotinylated anti-rabbit lgG & Horse & Vector Laboratories & BA-1100 & $1: 100$ \\
\hline \multicolumn{5}{|l|}{ Anti-biotin dyes } \\
\hline Fluorescein avidin DCS & $\mathrm{N} / \mathrm{A}$ & Vector Laboratories & A-2011 & $1: 100$ \\
\hline Texas Red avidin D & $\mathrm{N} / \mathrm{A}$ & Vector Laboratories & A-2006 & $1: 100$ \\
\hline
\end{tabular}

$\mathrm{NIH}$, National Institutes of Health.

ZEN acquisition software (Zeiss) or a Leica SP5 microscope with LAS AF acquisition software (Leica Microsystems). Image stacks were taken at $0.75 \mu \mathrm{m}$ intervals with image sizes of $134.95 \mu \mathrm{m}(x) \times 134.95 \mu \mathrm{m}(y)$ from the Zeiss microscope and $144.72 \mu \mathrm{m}(x) \times 144.72 \mu \mathrm{m}(y)$ from the Leica microscope. Images were processed using ZEN 2012 Blue Edition (Carl Zeiss Microscopy), Application Suite X (version 3.0.2.16120; Leica Microsystems), and Photoshop CC (Adobe Systems).

Hair cell and synapse ribbon counting. For hair cell and synapse ribbon counting, cochleae for each control and postnoise group were dissected, prepared for whole mounting, and immunostained for hair cell markers Myosin-VIIa or PCP-4 and the presynaptic ribbon marker CtBP2. The whole mounts were confocal imaged in the 5.6, 8, 11.3, 16, 22.6, 32, 45, and $64 \mathrm{kHz}$ frequency regions. Hair cells and $\mathrm{CtBP} 2^{+}$synapse ribbons were counted per region. Counts from each sample per time point were then averaged for the individual frequencies and are presented as the mean \pm SEM.

Quantification of Sox $10^{+} / \mathrm{DAPI} I^{+}$and Pan-QKI $/$Sox $10^{+} / \mathrm{DAPI} I^{+}$glial cells. Sections containing either apical and middle or middle and basal regions were taken from $Q K I^{F L / F L ;-}$ and $Q K I^{F L / F L ; P L P C r e E R T}$ mice $(n=4$ mice/group; 2-4 sections analyzed per mouse). Each section was immunostained with Pan-QKI to detect all QKI variants, with Sox10 to mark glial cells, and with DAPI to show cell nuclei. Sections were analyzed by confocal microscopy, and measurements were taken from maximum intensity projections of slice stacks per section. Similar areas of measurement were chosen for each osseous spiral lamina (OSL) and Rosenthal's canal (RC) region from the samples. Sox $10^{+} / \mathrm{DAPI}^{+}$cells (i.e., glial cells) and Pan-QKI ${ }^{+} /$Sox $10^{+} / \mathrm{DAPI}^{+}$cells (i.e., glia expressing QKI) were counted and cell densities were calculated as the number of cells counted divided by the area measured. Sox $10^{+} / \mathrm{DAPI}^{+}$and Pan-QKI ${ }^{+} / \mathrm{Sox} 10^{+} /$ $\mathrm{DAPI}^{+}$cell densities for $\mathrm{QKI} I^{\text {FL/FL;- }}$ and $\mathrm{QKI} I^{\text {FL/FL;PLPCreERT }}$ mice were tested for significant difference $(p<0.05)$ using the nonparametric Mann-Whitney test and plotted as mean \pm SEM values.

Transmission electron microscopy and observation of abnormal myelin. Sample preparation procedures for transmission electron microscopy (TEM) were modified from a previous publication (Lang et al., 2015). Briefly, deeply anesthetized mice were cardiac perfused with a mixture of $10 \mathrm{ml}$ of saline and $0.1 \%$ sodium nitrite solution, followed by $15 \mathrm{ml}$ of $4 \%$ paraformaldehyde and $2 \%$ glutaraldehyde in $0.1 \mathrm{~m}$ phosphate buffer, $\mathrm{pH}$ 7.4, fixative solution. The same fixative solution was used to perfuse the excised cochleae through the round window and for further immersion overnight at $4^{\circ} \mathrm{C}$. Cochleae were then decalcified using a $0.12 \mathrm{~m}$ EDTA solution at RT for 2-3 d with a magnetic stirrer. Cochleae were postfixed using a $1 \%$ osmium tetroxide and $1.5 \%$ ferrocyanide solution for $2 \mathrm{~h}$ in the dark, subsequently dehydrated, and then embedded in Epon LX 112 resin. Semithin sections for pre-TEM observation of AN orientation were cut with a $1 \mu \mathrm{m}$ thickness and stained with toluidine blue. Once a coronal plane for a given cochlear turn could be observed, ultrathin sections at $70 \mathrm{~nm}$ thickness were cut and stained with uranyl acetate and lead citrate and then examined using a JEOL JEM-1010 transmission electron microscope.

Myelin pathology of the ANs of control and $106 \mathrm{~dB}$ SPL noiseexposed, young-adult CBA/CaJ mice at days 1,14 , and 30 were processed for TEM. Electron micrographs from CBA/CaJ control and day 1 animals were used for quantitative analysis of myelin. Myelination of type I SGNs was visually inspected for the compactness of the lamellae. Noncompactness was classified as having spaces between opposing myelin layers and the absence of major dense line formation. The percentages of SGNs with noncompact myelin sheaths were calculated and plotted as the mean \pm SEM. Electron micrographs of AN fibers were collected from mutant $Q K I^{F L / F L ; P L P C r e E R T}$ and control QKI $I^{F L / F L ;-}$ cochleae. Myelin thickness, axonal diameters, and $\mathrm{G}$ ratios were measured using the open-source imaging software Fiji (Schindelin et al., 2012; RRID:SCR_002285), with the G Ratio for ImageJ plug-in (gratio.efil.de) using the developer instructions.

\section{Results}

\section{Functional declines and pathological alterations in the cochlea in response to noise exposure}

We first characterized pathophysiological alterations in cochleae of adult CBA/CaJ mice exposed to octave-band noise $(8-16 \mathrm{kHz})$ at 100,106 , or $112 \mathrm{~dB}$ SPL for $2 \mathrm{~h}$. Auditory brainstem responses were measured at several time points after noise exposure to evaluate AN function. As shown in Figure $1 a$, a $100 \mathrm{~dB}$ (SPL) exposure induced wave I threshold shifts up to $\sim 55 \mathrm{~dB}$ immediately after exposure. However, thresholds improved rapidly with nearly complete recovery by $7 \mathrm{~d}$ after exposure. For noise exposure at SPLs of 106 and $112 \mathrm{~dB}$, threshold shifts up to $\sim 65 \mathrm{~dB}$ were seen Im (Fig. $1 b, c)$. Although wave I thresholds improved by day 3, permanent threshold shifts (PTSs) of $>20 \mathrm{~dB}$ were present at $16 \mathrm{kHz}$ and higher-frequency regions for the $106 \mathrm{~dB}$ exposure (Fig. 1b), and 

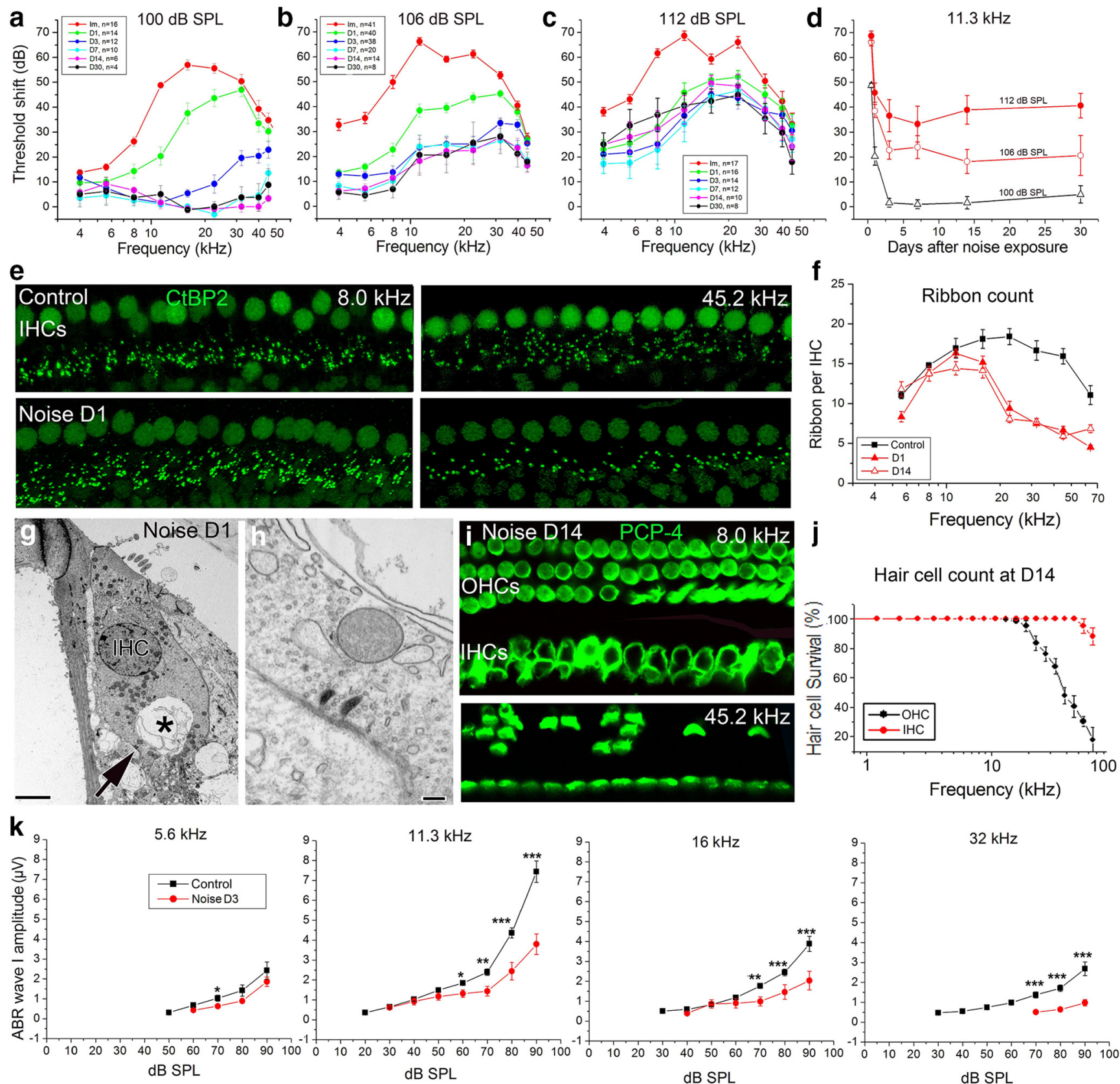

Figure 1. Noise-induced functional declines in the young adult CBA/CaJ mouse AN. ABR wave I threshold shifts as a function of frequency showed dynamic alterations $I \mathrm{~m}$, and $1 \mathrm{~d}$ (D1), $3 \mathrm{~d}$ (D3), $7 \mathrm{~d}$ (D7), $14 \mathrm{~d}$ (D14), and $30 \mathrm{~d}$ (D30) after noise exposure. $\boldsymbol{a}-\boldsymbol{c}$, The mice were exposed to an 8-16 kHz octave-band noise at 100 (a), 106 (b), or 112 (c) dB SPL for $2 \mathrm{~h}$. $\boldsymbol{d}$, Mean ABR wave I threshold shifts at $11.3 \mathrm{kHz}$ showed $>20 \mathrm{~dB}$ declines at D3 to D30 after exposure to 106 and $112 \mathrm{~dB}$ noise, but recovered rapidly to near-normal levels after a $100 \mathrm{~dB}$ SPL exposure. Data from mice of both sexes are included in all physiological studies, as their ABRs are not significantly different before and after noise (data not shown). $\boldsymbol{e}-\boldsymbol{h}$, There was a marked loss of ribbon synapses under inner hair cells (IHCS) at frequency regions $>22.3 \mathrm{kHz}$ at both D1 and D14 after $106 \mathrm{~dB}$ SPL noise exposure. Ribbon synapses and IHC nuclei were visualized with anti-CtBP2 antibody (green) in control (e, top) and D1 noise-exposed mice (e, bottom) at the 8 and $45.2 \mathrm{kHz}$ regions. $\boldsymbol{f}$, Ribbon counts under IHCs revealed a $>50 \%$ loss of CtBP2 ${ }^{+}$synapses at the $22.3 \mathrm{kHz}$ and higher-frequency regions at both D1 and D14 after noise exposure. $\boldsymbol{g}$, An electron micrograph from the $22.6 \mathrm{kHz}$ region reveals vacuole-like spaces filled with debris $\left(^{*}\right)$ in the afferent terminal regions under an IHC at D1 after $106 \mathrm{~dB}$ exposure. $\boldsymbol{h}$, An enlarged image of the region, identified by a black arrow in $\boldsymbol{g}$ illustrates two remaining ribbon synapses. $\boldsymbol{i}$, Staining of hair cells with an antibody to PCP-4 revealed outer hair cell (OHC) losses in higher-frequency regions at D14 after a $106 \mathrm{~dB}$ exposure. $\boldsymbol{j}, \mathrm{PCP}-4^{+}$cell counts document $\mathrm{OHCl}$ losses at $16 \mathrm{kHz}$ and in higher-frequency regions at D14 after $106 \mathrm{~dB}$ noise exposure. $\boldsymbol{k}$, Wave I amplitudes were reduced at $5.6,11.3,16$, and $32 \mathrm{kHz}$ at D3 after $106 \mathrm{~dB}$ noise exposure $\left({ }^{*} p<0.05,{ }^{* *} p<0.01\right.$, and ${ }^{* * *} p<0.001$, Mann-Whitney test; Figure 1-1 available at https://doi.org/ 10.1523/JNEUROSCI.2487-17.2018.f1-1, exact statistical output). All data were presented as mean \pm SEM.

of $>35 \mathrm{~dB}$ at $5.6 \mathrm{kHz}$ and higher-frequency regions for the $112 \mathrm{~dB}$ exposure (Fig. 1c). A comparison of threshold shifts for the 11.3 $\mathrm{kHz}$ stimulus at all three SPL levels of noise exposure is provided in Figure $1 d$. Because the 106 and $112 \mathrm{~dB}$ noise levels induced PTS in most frequency regions, these two noise levels were chosen for use in subsequent experimentation.
The effect of noise exposure at $106 \mathrm{~dB}$ SPL on afferent synaptic ribbons was evaluated quantitatively by immunostaining flat preparations of the basilar membrane with anti-C-terminal binding protein (CtBP2; Khimich et al., 2005). CtBP2 ${ }^{+}$presynapse losses of $\sim 50 \%$ were seen for frequency regions $>16 \mathrm{kHz}$ (Fig. 1e) at both days 1 and 14 (Fig. 1f). Electron micrographs revealed 

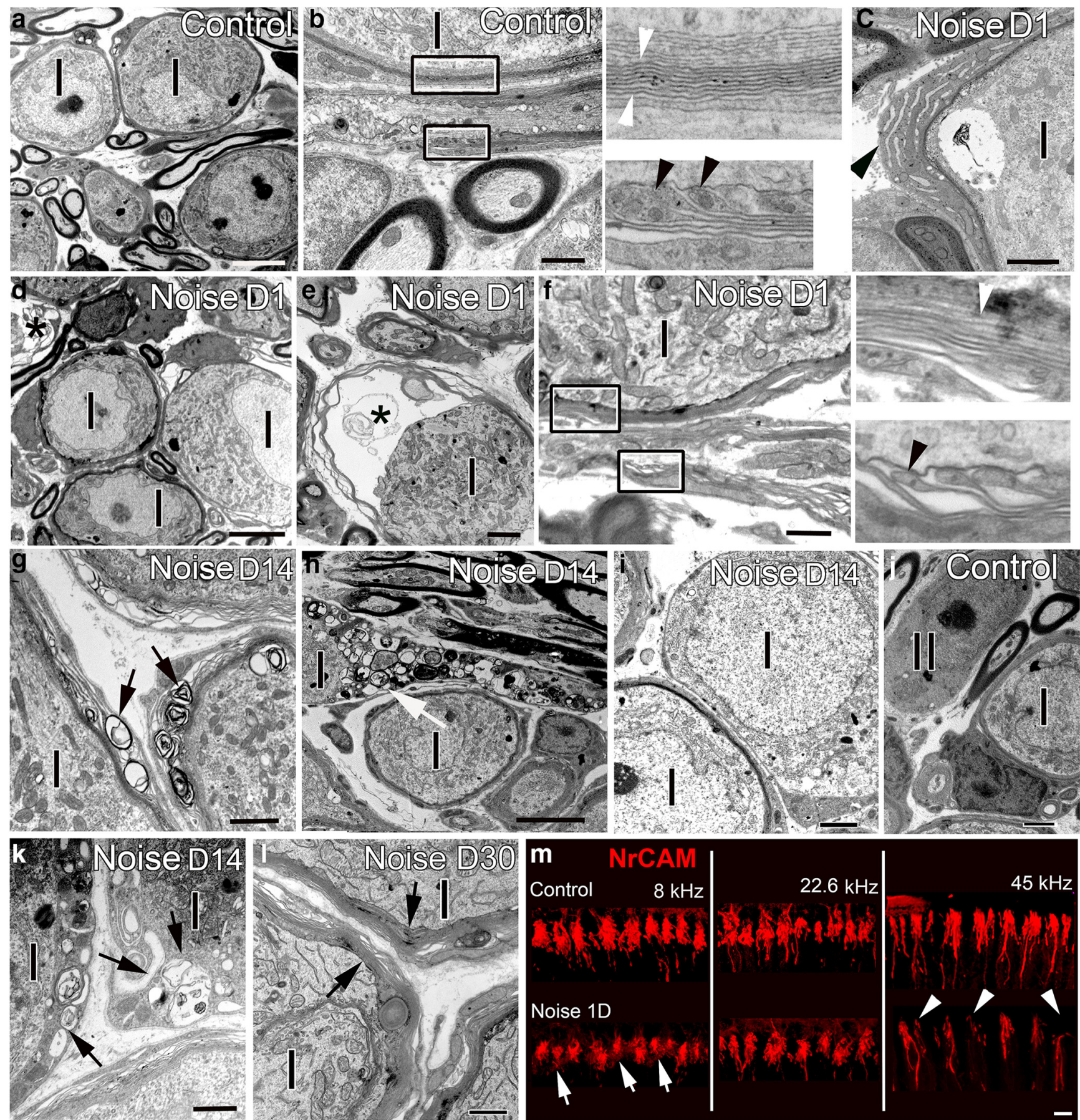
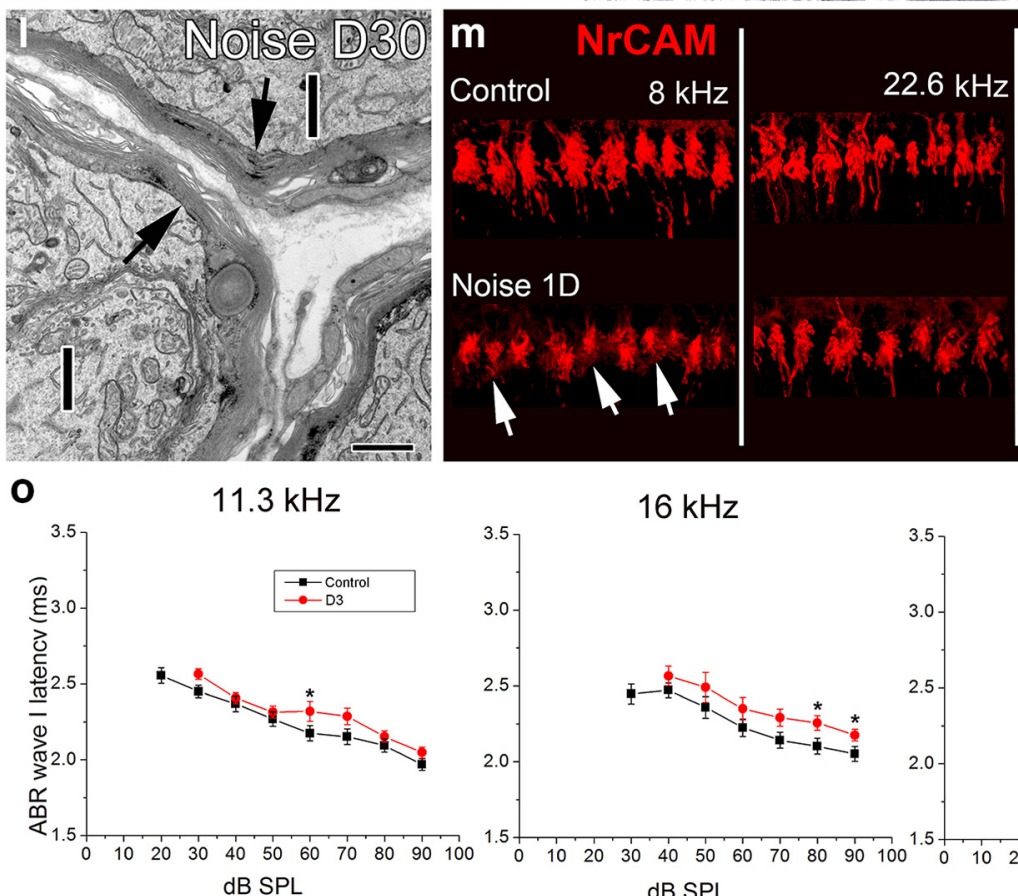

$16 \mathrm{kHz}$
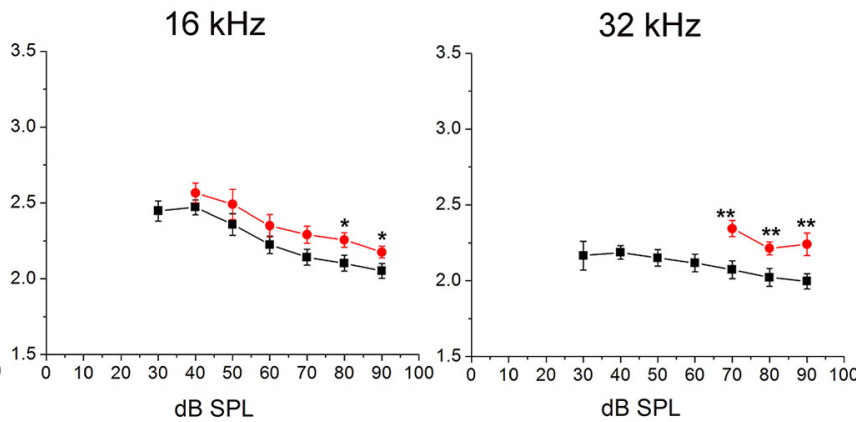

Figure 2. Noise-induced demyelination and disruption of paranodal axoglial junctions. $\boldsymbol{a}, \boldsymbol{b}$, Normal type I (I) SGNs and their myelinating glial cells in an adult CBA/CaJ mouse. The panel to the right of $\boldsymbol{b}$ shows enlargements of the boxed areas in $\boldsymbol{b}$. The top image shows compact myelin lamellae (white arrowheads), and the bottom image shows paranodal axo-glial junctions (black arrowheads). c $\mathbf{- f}$, One day after $106 \mathrm{~dB}$ SPL noise exposure for $2 \mathrm{~h}$, the compact lamellae of myelin sheaths are disrupted. c $\boldsymbol{f}$, Disruption of the myelin (Figure legend continues.) 
that the synapse ribbons, which remained at day 1, appeared to have normal ultrastructural features (Fig. 1 $g, h$ ). Evaluation of hair cells by immunodetection of PCP-4 (Purkinje cell protein 4), a recently identified putative hair cell marker (Ku et al., 2014), showed that $106 \mathrm{~dB}$ noise elicited a loss of outer hair cells at frequency regions $\geq 22.6 \mathrm{kHz}$ at day 14 after exposure (Fig. $1 i, j$ ). Losses of inner hair cells were detected only for frequency regions $\geq 45.2 \mathrm{kHz}$ (Fig. 1i,j). A significant reduction of ABR wave I amplitudes was seen at $5.6 \mathrm{kHz}$ and higher-frequency regions after exposure (Fig. $1 k$ and Fig. 1-1 available at https://doi.org/10.1523/ JNEUROSCI.2487-17.2018.f1-1, exact statistical output).

\section{Structural changes in myelin and axo-glial junctions following noise exposure}

Our previous studies of mouse and human cochleae demonstrated that myelin abnormalities occur before a significant AN loss, suggesting that glial dysfunction plays a critical role in the early phase of AN degeneration in sensorineural hearing loss (Xing et al., 2012). To investigate this supposition, we examined ultrastructure of myelinating glia in mice exposed to 106 or 112 $\mathrm{dB}$ noise. Since this exposure paradigm induces PTS in the frequency range of $\geq 16 \mathrm{kHz}$ (Fig. $1 b, c$ ), sections from 16 to $45.6 \mathrm{kHz}$ regions of the cochlea were selected for TEM examination. Electron micrographs from control mice showed that type I SGNs are ensheathed with multiple layers of compact myelin lamellae proximal to the glia and multiple layers of noncompact myelin lamellae proximal to the neuron (Fig. 2a,b). Myelinating cells enclosing axons often have only compact myelin (Fig. 2b). Myelin paranodal loops were seen to be in tight contact with axons through axo-glial junctions (Fig. 2b). Loss/disruption of myelin was frequently observed in the AN nerve within RC Im and on day 1 (Fig. $2 c-e$ ), whereas no gross pathological alterations were seen in the neuronal bodies (Fig. 2). Disruptions were also present in paranodal axo-glial junctions (Fig. 2f). Myelin abnormalities were more pronounced at day 14 and included loss/disruption of compact myelin lamellae, the appearance of degenerative myelin whorls (Fig. $2 g, k$ ), and disruption of and, in some cases, a total loss of myelin sheaths (Fig. 2h,i). At day 30, pathological alterations in myelin were still present in the mice exposed to $106 \mathrm{~dB}$ noise (Fig. $2 l$ ). In randomly selected sections from the middle turn and middle portion of the basal turn of noise-exposed cochleae among all the mice examined, 225 of 288 identifiable glial cells exhibited at least one of the myelin abnormalities described above. These myelin abnormalities were found in 165 of 215 glial cells at day 1 and in 60 of 73 glial cells at day 14. By comparison, only 41 of 143 glial cells seen in control samples exhibited similar myelin abnormal-

\section{$\longleftarrow$}

(Figure legend continued.) sheath surrounding neurons, often with large separations (black arrowhead in $\boldsymbol{c}$, asterisks in $\boldsymbol{d}$ and $\boldsymbol{e}$, white arrowhead in $\boldsymbol{f}$ ) and disruption of axo-glial junctions (black arrowhead in $\boldsymbol{f}$ ). The panel to the right of $\boldsymbol{f}$ contains enlarged images of the boxed areas in $\boldsymbol{f} . \boldsymbol{g}, \boldsymbol{h}, \boldsymbol{k}$, Fourteen days (D14) after noise exposure, demyelination of SGNs was associated with numerous myelin whorls and cytoplasmic vacuolization (black arrows in $\boldsymbol{g}$ and $\boldsymbol{k}$, and white arrow in $\boldsymbol{h}$ ). At D14, a typical type I SGN was seen ensheathed by a single layer of satellite glial cell cytoplasm lacking myelin (i) as occurs in type II (II) neurons of the control AN (j). I, At D30, most glial cells ensheathing type I SGNs have lost their compact myelin lamellae (black arrows). $\boldsymbol{m}$, A reduction (arrows) and eventual loss (arrowheads) of $\mathrm{NrCAM}^{+}$nodal structures were seen in the habenula at D1 after $112 \mathrm{~dB}$ SPL noise exposure. $\boldsymbol{n}$, The percentage of SGNs with abnormal myelin sheaths was greatly increased at D1 after $106 \mathrm{~dB}$ SPL exposure. $\mathbf{0}$, Delayed wave I latencies were present at 11.3, 16, and $32 \mathrm{kHz}$ at D3 after $106 \mathrm{dBSPL}$ noise exposure $\left({ }^{*} p<0.05\right.$ and ${ }^{* *} p<0.01$, Mann-Whitney test; Figure 2-1 available at https://doi.org/ 10.1523/JNEUROSCI.2487-17.2018.f2-1, exact statistical output). Data are presented as the mean \pm SEM. Scale bars: $\boldsymbol{a}, \boldsymbol{d}, 3 \mu \mathrm{m} ; \boldsymbol{b}, \boldsymbol{c}, \boldsymbol{f}, \boldsymbol{g}, \boldsymbol{k}, \boldsymbol{I}, 800 \mathrm{~nm} ; \boldsymbol{e}, \boldsymbol{i}, \boldsymbol{j}, 2 \mu \mathrm{m} ; \boldsymbol{h}, 5 \mu \mathrm{m} ; \boldsymbol{m}, 4 \mu \mathrm{m}$. ities. Approximately $77 \%$ of glial cells observed in ears on day 1 and $29 \%$ of glial cells in controls had abnormal myelin levels (Fig. $2 n ; n=3$ mice/group).

Neuronal cell adhesion molecule (NrCAM) is expressed in the nodal axolemma and plays an important role in maintenance of the axon initial segment and the nodes of Ranvier (Amor et al., 2014). Immunostaining of the AN with anti-NrCAM antibody at day 1 revealed a loss of axon initial segments (heminodal) at the habenula (Hab) opening in regions encoding frequencies of $\geq 8$ $\mathrm{kHz}$ (Fig. $2 \mathrm{~m}$ ). A significant delay of ABR wave I latencies was seen in frequency regions $\geq 11.3 \mathrm{kHz}$ after noise exposure (Fig. $2 o$ and Fig. 2-1 available at https://doi.org/10.1523/JNEUROSCI. 2487-17.2018.f2-1, exact statistical output). These results were consistent with the appearance of myelin abnormalities and the disruption of paranodal structures at similar frequencies, perhaps leading to slower conduction velocities.

\section{Involvement of macrophages in demyelination after noise exposure}

Macrophages contribute to the process of nerve degeneration by phagocytosing myelin debris and axonal remnants. Macrophage recruitment/migration into the cochlea has been reported to occur following noise-induced cochlear insult (Hirose et al., 2005; Sautter et al., 2006), ototoxic drug-induced SGN degeneration (Lang et al., 2016), and genetic modification-induced hair cell loss (Kaur et al., 2015). To validate the presence of macrophages in the AN, sections from control and noise-exposed ears were immunostained with Iba-1, a key calcium binding protein that is expressed by microglia/macrophages, but not neural cells (Nakamura et al., 2013). Iba- $1^{+}$macrophages were present in several regions of the $\mathrm{AN}$ in noise-exposed cochleae (Fig. $3 a-e$ ). Like monocytes/macrophages, neutrophils are also often seen in injured tissues (de Oliveira et al., 2016). Immunostaining for lymphocyte antigen 6 complex locus G6D (Ly6G), a commonly used marker for granulocytes/neutrophils (Daley et al., 2008), identified $\mathrm{Ly}_{6 \mathrm{G}}{ }^{+}$cells in the control cochlear bone marrow (Fig. $3 f$ ) but did not identify any $\mathrm{Ly}_{6 \mathrm{G}}{ }^{+}$neutrophils in the ANs of either noise-exposed or control mice (Fig. $3 g-i$ ). These findings suggest that monocytes/macrophages, but not granulocytes/neutrophils, are involved in AN degeneration after exposure. Further support for this is provided by examination of ultrathin sections from control and noise-exposed mice. Macrophages were often present in regions of myelin degeneration at both days 1 and 14 after exposure (Fig. $3 k-p$ ). Ensheathment of abnormal-appearing neurites by macrophage processes (Fig. $3 \mathrm{~m}$ ) supports the involvement of activated macrophages in demyelination following noise exposure. Very few macrophages were seen in the ANs of controls or at day 30; when present, these macrophages were surrounded by normal-looking axons (Fig. 3j,q).

\section{Gene expression analysis identifies noise-induced effects on genes associated with inflammation and myelin}

To understand molecular changes following noise exposure, we performed microarray transcriptional profiling on ANs from control adult mice and mice Im, or on days 1,7 , or $14(n=3$ per group). Differential expression analysis identified 1247 probe sets corresponding to 901 unique genes that were significantly different among the pairwise relationships (Fig. 4 and Fig. 4-1 available at https://doi.org/10.1523/JNEUROSCI.2487-17.2018.f4-1). Notably, the comparison excluded 48 genes detected as differentially expressed based on animal sex in a preliminary analysis of expression data (Fig. 4-2 available at https://doi.org/10.1523/JNEUROSCI. 2487-17.2018.f4-2). Examination of expression patterns for the 

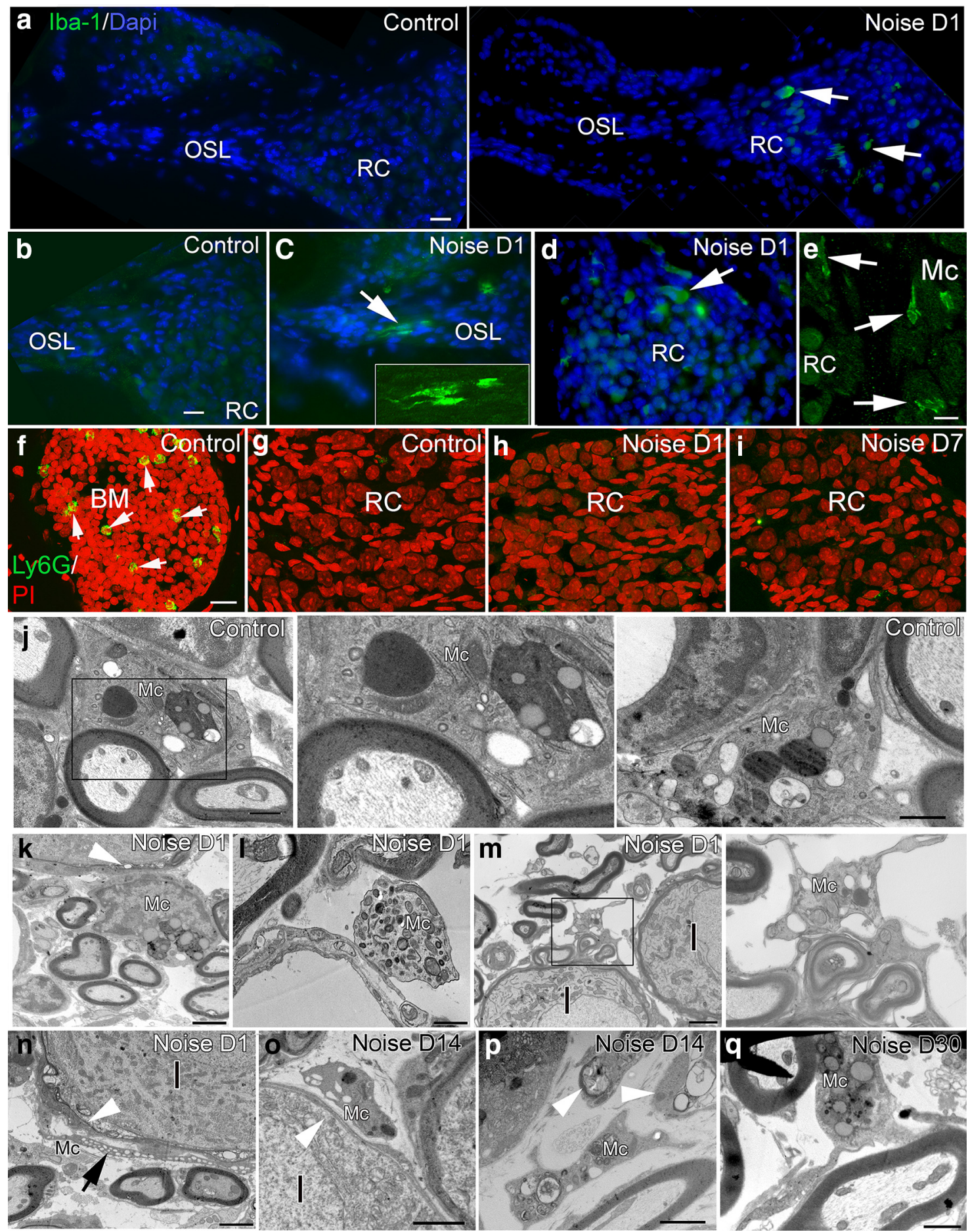

Figure 3. Macrophages appear to be recruited to and activated in regions of noise-induced demyelination. $\boldsymbol{a}$, Low-magnification images immunostained for Iba- 1 from a control cochlea (left) and a cochlea at $1 \mathrm{~d}$ (D1) after exposure to $106 \mathrm{~dB}$ noise for $2 \mathrm{~h}$ (right). OSL and RC regions are indicated. White arrows indicate lba-1-positive cells. c-e, Immunostaining for Iba-1 revealed many macrophages (Mc) within the OSL (c) and RC (d, $\boldsymbol{e})$ at D1 after noise exposure. $\boldsymbol{b}$, No Iba- ${ }^{+}$cells were seen in the OSL or RC of control non-noise-exposed cochlear sections. Nuclei were counterstained with DAPI $(\boldsymbol{a}-\boldsymbol{d}) . \boldsymbol{f}$, Ly6G-positive cells (green, white arrows) are present in the bone marrow of a young adult control mouse. $\boldsymbol{g}-\boldsymbol{i}$, No Ly6G ${ }^{+}$cells could be found in the ANs of control or noise-exposed mice at D1 or D7 after $106 \mathrm{~dB}$ SPL noise exposure ( 3 animals examined per experimental condition; 2 sections analyzed per animal; sections contained either apical and middle or middle and basal regions). Nuclei were counterstained with PI ( $\boldsymbol{f}-\boldsymbol{i}) . \boldsymbol{j}$, A macrophage is present among three AN axons in a control cochlea section (left). Middle, An enlarged image of the boxed area of the left panel. Right, A macrophage is shown next to a blood vessel and some AN fibers in a control cochlea. $\boldsymbol{k}-\boldsymbol{p}$, Numerous macrophages appeared in regions with myelin abnormalities at D1 $(\boldsymbol{k}-\boldsymbol{n})$ and D14 $(\boldsymbol{o}, \boldsymbol{p})$ after noise exposure. White arrowheads indicate an empty space in a myelin sheath $(\boldsymbol{k})$, a fused myelin sheath ( $\boldsymbol{n})$, and a type ISGN ensheathed by only one layer of myelin $(\boldsymbol{o})$. Most macrophages contained numerous inclusion bodies with electron-dense contents resembling myelin and often were seen closely apposed to segments of myelin sheath $(\boldsymbol{m})$. The panel to the right of $\boldsymbol{m}$ shows an enlarged image of the boxed area in $\boldsymbol{m}$. At D14, macrophages appear to have engulfed many segments of degenerating axons (white arrowheads in $\boldsymbol{p}$ ). $\boldsymbol{q}$, At D30, macrophages with numerous inclusions containing electron-dense material are still present in regions of remaining healthy-looking AN fibers. Scale bars: $\boldsymbol{a}, 20 \mu \mathrm{m} ; \boldsymbol{b}$ (for $\boldsymbol{b}-\boldsymbol{d}), 10 \mu \mathrm{m} ; \boldsymbol{e}, 8 \mu \mathrm{m} ; \boldsymbol{f}$ (for $\boldsymbol{g}-\boldsymbol{i})$, $10 \mu \mathrm{m} ; \boldsymbol{j}(\mathrm{left}), \boldsymbol{k}, \boldsymbol{m}-\boldsymbol{q}, 2 \mu \mathrm{m} ; \boldsymbol{j}$ (right), $\boldsymbol{l}, 800 \mathrm{~nm}$. 
a

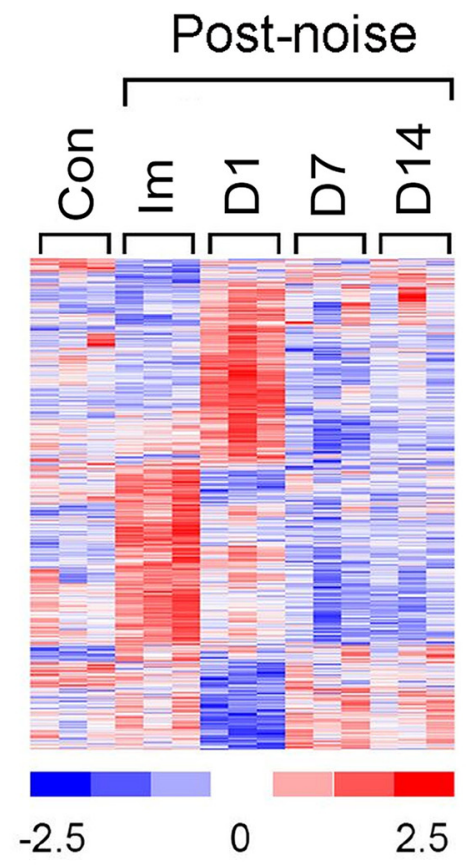

b

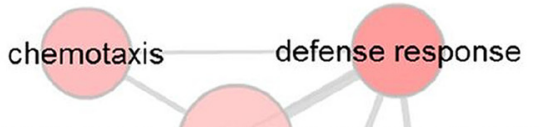

cellular response to DNA damage stimulus

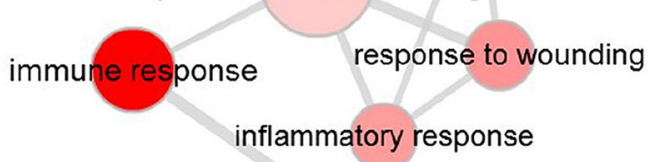

antigen processing and presentation of exogenous antigen
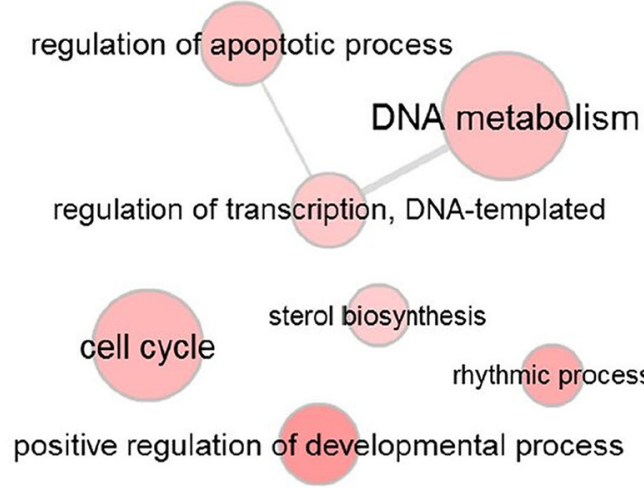

C

\section{Post-noise}

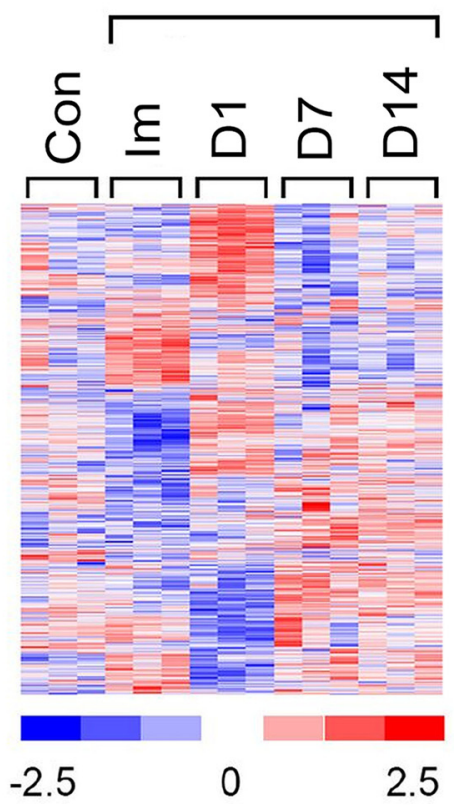

Figure 4. Gene expression responses in the noise-injured AN. $a$, Microarray analysis identified 1247 gene representations (probe sets) that were differentially expressed following noise exposure (Figure 4-1 available at https://doi.org/10.1523/JNEUROSCI.2487-17.2018.f4-1). Time points evaluated after noise exposure were Im following exposure, and 1d (D1), $7 \mathrm{~d}$ (D7), and 14d (D14) after exposure. Differential expression was defined as a fold change of $>1.5$ and $p<0.05$ (Student's unpaired $t$ test) for any pairwise relationship among control and noise exposure samples; the false discovery rate for this analysis was $\sim 24.1 \%$. Microarray analyses exclude genes found to be different solely as a function of sex (Figure 4-2 available at https://doi.org/10.1523/JNEUROSCI.248717.2018.f4-2). $\boldsymbol{b}$, Enrichment analysis results for gene ontology biological process terms associated with differentially expressed genes shown in $\boldsymbol{a}$. Enrichment was performed with DAVID and significant terms ( $p<0.05$, Benjamini-Hochberg adjusted) were summarized with REVIGO. Node intensity reflects significance score; node size reflects the number of differentially expressed genes. $c$, Microarray expression profiles of 1560 myelin-related genes (probe sets) that were affected by noise exposure ( $p<0.05$, Student's unpaired $t$ test; Figure 4-3 available at https://doi.org/10.1523/ JNEUROSCI.2487-17.2018.f4-3). Myelin-related genes for analysis were compiled from published studies (Zhang et al., 2014; Thakurela et al., 2016) and internet resources (see Materials and Methods).

noise-responsive genes showed that most exhibited transient upregulation or downregulation after exposure that peaked in Im or day 1 samples but returned to near-normal levels in day 14 samples (Fig. 4a). Analysis of biological processes enriched among all of the differentially expressed genes detected a core set of related processes associated with wounding and inflammation (Fig. $4 b$, top network), including the process that had the overall highest enrichment score, immune response ( $\left.p_{\text {adj }}=5.9 \mathrm{E}-08\right)$. Also enriched among the differentially expressed genes was a set associated with apoptosis and DNA metabolism (Fig. $4 b$, middle network) and independent processes that included cell cycle and positive regulation of development (Fig. $4 b$, bottom).

To address the myelin pathologies observed following noise exposure, we specifically examined expression data for myelinrelated genes. The list of myelin genes interrogated was compiled from several sources, including the gene ontology database and datasets produced from recent RNA-sequencing profiling of myelinating cells (Zhang et al., 2014; Thakurela et al., 2016). The compiled myelin list comprised 1849 unique genes that in turn corresponded to 3510 probe sets for the microarray platform used in our experiments. Analysis of the expression of these genes in response to noise found that approximately half were statistically different $(p<0.05)$ for at least one pairwise relationship in our dataset $(1063$ of 1849 unique genes $=57 \% ; 1560$ of 3510 probe sets $=44 \%$; Fig. $4-3$ available at https://doi.org/10.1523/ JNEUROSCI.2487-17.2018.f4-3). Clustering analysis of expression patterns for these genes again showed that many underwent transient upregulation or downregulation that peaked in Im or day 1 samples (Fig. 4c).

\section{Quaking and its potential target genes in the AN are affected} by noise exposure

Among genes differentially expressed in response to noise, the QKI gene is well characterized as a key regulator for the formation and maintenance of myelin and axo-glial junctions in the CNS (Darbelli et al., 2016). The QKI gene generates three major spliced transcripts encoding QKI-5, QKI-6, and QKI-7 isoforms (Ebersole et al., 1996). Here we examined the expression of Pan-QKI and specific variants in response to noise. Quantitative PCR analysis of isoform expression in the mouse AN $1 \mathrm{~d}$ after noise exposure revealed significant change in QKI-7 but not in QKI-5 and QKI-6 (Fig. 5a). These data, coupled with our findings of differential expression of QKI by microarray, demonstrated that QKI isoform expression is altered in response to noise and suggests that targets of QKI may also be affected. We therefore reanalyzed the microarray expression data to examine putative targets of QKI, compiling a list of 1416 mRNAs containing the QRE, a bipartite consensus binding sequence (Galarneau and Richard, 2005), and 28 RNAs detected as differentially spliced in mouse oligodendrocytes (Darbelli et al., 2016). Collectively, the list of putative QKI targets corresponded to 3102 probe sets on the microarray platform used for our study. Query of these probe sets revealed that 1297 (42\%) were statistically different $(p<0.05$, Student's $t$ test, unpaired) for at least one pairwise relationship in our dataset (Fig. 5-1 available at https://doi.org/10.1523/JNEUROSCI.248717.2018.f5-1). Clustering analysis of expression patterns for these putative QKI targets regulated by noise again showed that most underwent transient upregulation or downregulation peaking Im or at day 1 after noise exposure (Fig. $5 b$ ). 

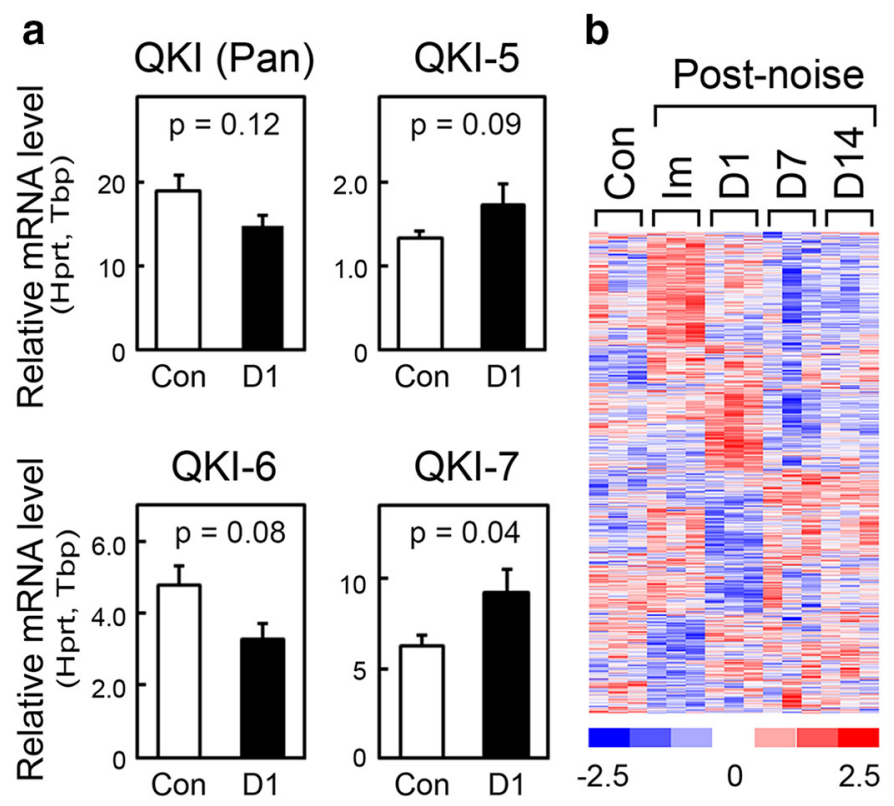

e
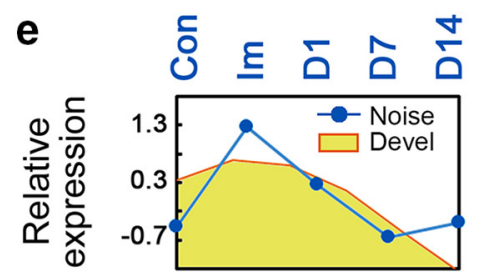

Cluster 1

(22 genes)

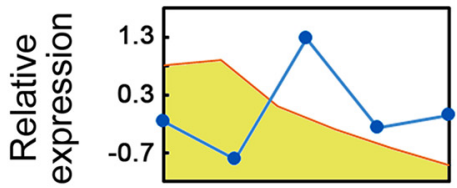

Cluster 2

(25 genes)

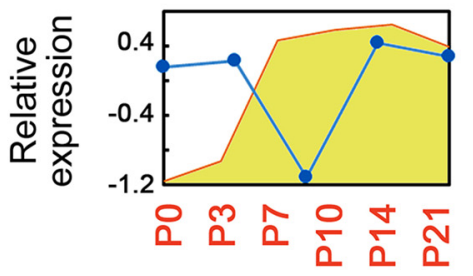

Cluster 3

(51 genes)
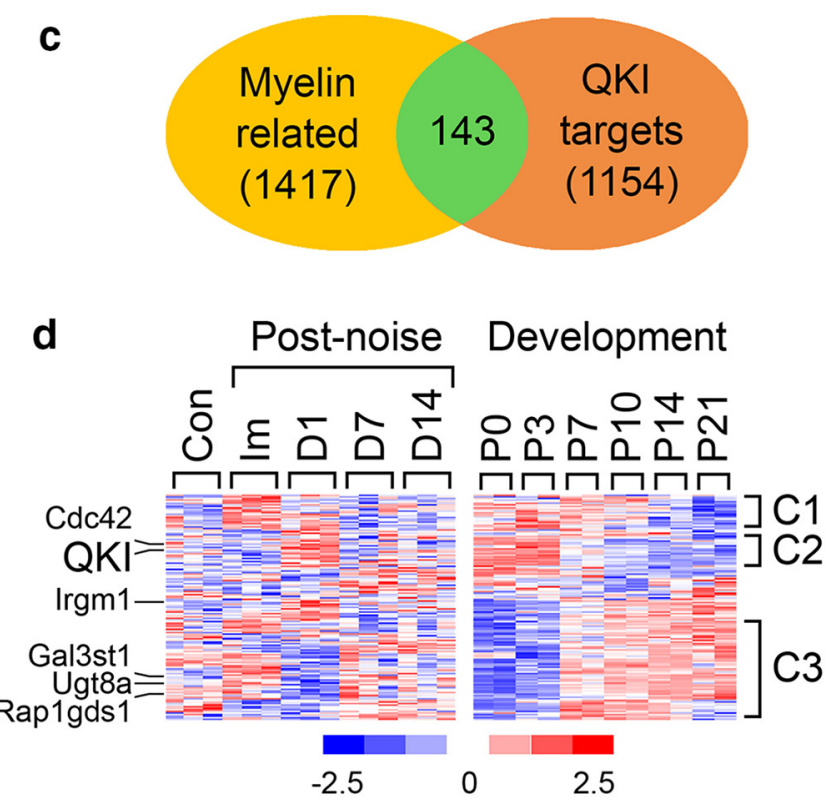

Myelin and QKI target

Immune response / inflammation

Other

Figure 5. Expression patterns of QKI variants and potential targets of QKI in response to noise injury. $\boldsymbol{a}$, Relative expression levels of all QKI mRNA (Pan) and QKI variants measured by qPCR analysis of AN in control (Con) mice and mice at $1 \mathrm{~d}$ (D1) after noise exposure. Expression levels shown are normalized to Hprt (hypoxanthine phosphoribosyltransferase) and Tbp (TATA-Box Binding Protein); error bars indicate SD; $p$ values shown are for unpaired Student's $t$ tests. $\boldsymbol{b}$, Microarray expression profiles for potential QKI target genes that are differentially expressed following noise exposure (Figure 5-1 available at https://doi.org/10.1523/JNEUROSCI.2487-17.2018.f5-1). Putative QKI targets for analysis were compiled from studies by Galarneau and Richard (2005) and Darbelli et al. (2016). Differential expression was defined as $p<0.05$ (Student's unpaired $t$ test) for any pairwise relationship among control and noise exposure samples. c, Venn diagram depicting overlap between the group of myelin-related genes regulated by noise exposure (shown in Fig. 4c) and the group of putative QKI targets regulated by noise exposure. $\boldsymbol{d}$, Left, Microarray expression profiles for the 143 gene representations (probe sets) depicted in c that are myelin related, putative QKI targets and are differentially expressed in response to noise (Figure 5-2 available at https://doi.org/ 10.1523/JNEUROSCI.2487-17.2018.f5-2). Genes of interest are indicated to the left. Right, Expression profiles of the 143 genes in the developmental AN at P0 to P21. Microarray data were queried from our previous study (Lang et al., 2015). $\boldsymbol{e}$, Average relative ( $z$ standardization) expression patterns for clustered genes identified in $\boldsymbol{d}$. Relative noise responses are summarized by line graph (blue); relative developmental patterns are summarized by area graph (yellow). $\boldsymbol{f}$, Summarization of qPCR analyses performed to validate expression changes measured by microarray analysis. Log fold changes measured for D1 vs control comparisons are plotted for microarray analysis ( $x$-axis) vs qPCR analysis ( $y$-axis; Figure 5-3 available at https://doi.org/10.1523/JNEUROSCI.248717.2018.f5-3, exact statistical output).

Given the established relationship between QKI and myelin (Darbelli and Richard, 2016), we determined the overlap between the myelin-related genes affected by noise and the putative QKI targets affected by noise. Of the 1560 differentially expressed myelinrelated probe sets and the 1297 differentially expressed QKI target probe sets, 143 were both myelin-related and putative QKI targets (Fig. 5c,d and Fig. 5-2 available at https://doi.org/10.1523/ JNEUROSCI.2487-17.2018.f5-2). Unsurprisingly, QKI was one of the genes identified by this analysis; other genes of interest included Cdc42, Irgn1, Ugt8a, Egr2, Mal, Kcnal, NF1, and Nfasc.

QKI and its potential RNA targets in the adult cochlea fail to fully recapitulate their developmental regulatory patterns after noise exposure

Our previous study revealed that acute nerve injury caused transcriptional effects in the AN resembling a developmental transi- 

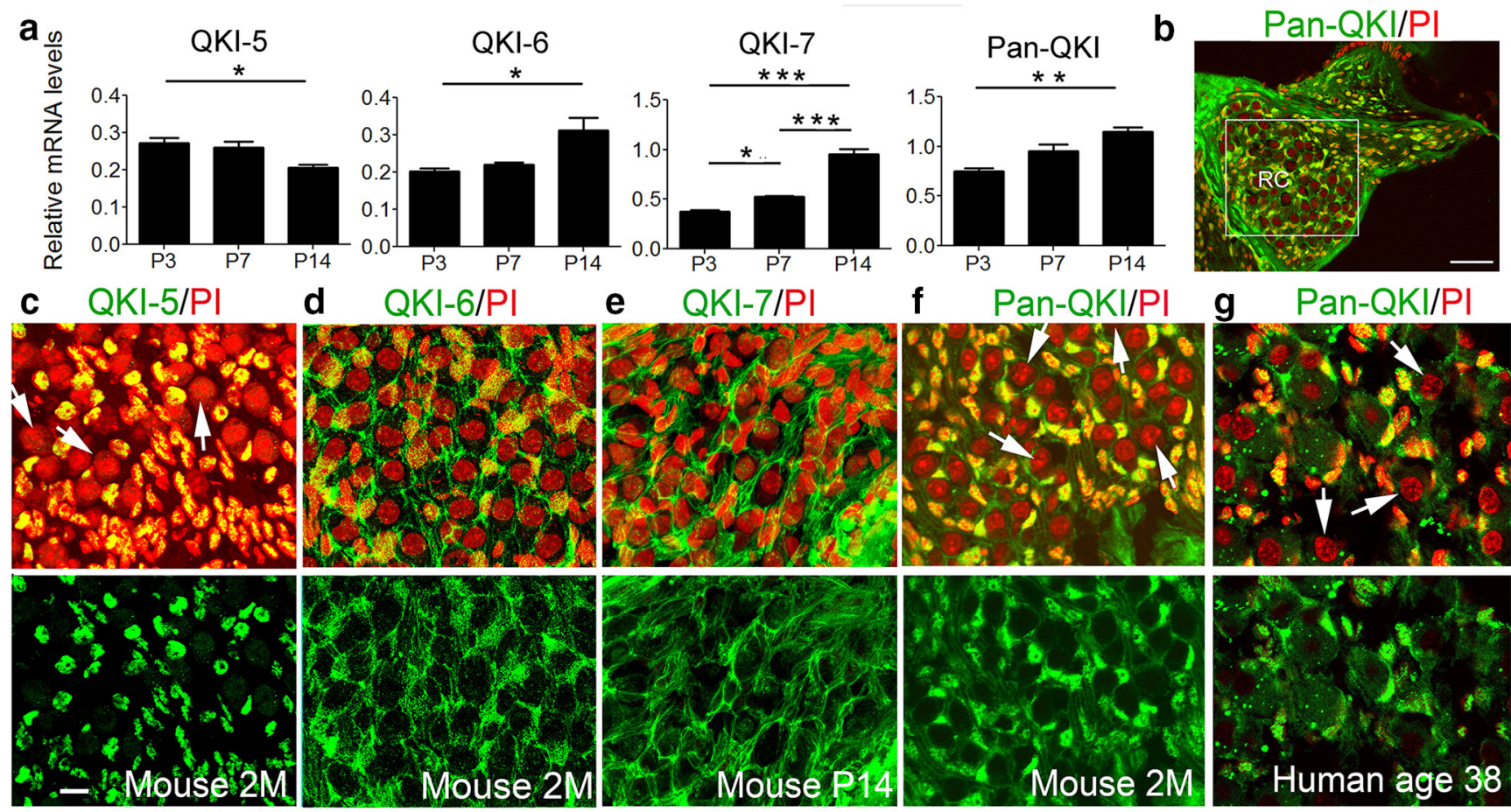

Figure 6. Expression patterns of QKI variants in normal postnatal and adult ANs. $\boldsymbol{a}$, Expression levels of QKI-5 mRNA decrease from P3 to P14, while QKI-6 and QKI-7 levels increase from P3 to P14, presenting a pattern similar to that seen for Pan-QKI. Relative expression levels of all QKI mRNA (Pan and QKI variants) were measured by qPCR analysis in the ANs of CBA/CaJ mice at P3, P7, and P14. Expression levels shown are normalized to Hprt and Actb; error bars indicate SEM; ${ }^{*} p<0.05,{ }^{* *} p<0.01$, and ${ }^{* * *} p<0.001$ by one-way ANOVA with Bonferroni's post-test (Figure 6-1 available at https://doi.org/10.1523/JNEUROSCI.2487-17.2018.f6-1, exact statistical output). $\boldsymbol{b}$, Low-magnification image of AN section immunostained with the anti-Pan-0KI highlighting location of RC where all images were obtained. $\mathbf{c}-\boldsymbol{g}$, Immunostaining with anti-QKI antibodies showing protein expression patterns of QKI isoforms in the glial cells but not neurons (white arrows) of the normal ANs from mice aged 2 months $(2 \mathrm{M} ; \boldsymbol{c}, \boldsymbol{d}, \boldsymbol{f})$ or $14 \mathrm{~d}(\boldsymbol{e})$, and temporal bone from a human ear, aged 38 years $(\boldsymbol{g})$. The nuclei were stained with PI. Scale bars: $\boldsymbol{b}, 50 \mu \mathrm{m} ; \boldsymbol{c}(\mathrm{for} \boldsymbol{c}-\boldsymbol{g}), 8 \mu \mathrm{m}$.

tion from the mature to the immature state (Lang et al., 2015). For example, AN injury caused upregulation of Sox 2 and other neural progenitor-related genes and increased the proliferation of a subset of glial cells. Specific temporal patterns of QKI expression in developing nerve tissue are associated with the states of glial cell differentiation and myelination. For example, the expression of QKI-6 and QKI-7 peak at approximately P14, coinciding with myelination of brain tissues (Ebersole et al., 1996; Hardy et al., 1996). We next examined whether this select group of genes, which are myelin related, and putative QKI targets, which are responsive to noise injury, also exhibited evidence of developmental regulation. To address this, we queried our previously described microarray dataset that profiled mouse auditory development from P0 to P21 (Lang et al., 2015), which covers a critical period for glial maturation and myelination. Clustering analysis of these genes (Fig. $5 d, e$ ) revealed that nearly all showed vivid patterns of upregulation or downregulation during the developmental period. Inspection of the heatmap involving both injury and development profiles identified three prominent clusters, with two (clusters 1 and 2) showing upregulation by noise and downregulation during development and the third (cluster 3 ) showing the opposing pattern of downregulation by noise and upregulation during development (Fig. 5e). Among these clusters, only cluster 1 showed temporal patterns for development and noise exposure that were fundamentally similar. For clusters 2 and 3, the developmental and injury temporal response patterns were largely opposing. Of the 143 myelin-related, putative QKI target, noise-responsive genes, 98 were present in these three clusters (69\%). Opposing temporal relationships were also apparent in the unclustered QKI targets, which contain 31\% of myelin-related QKI targets. These results highlight that there is similarity but also discordance in how putative QKI targets are regulated in the developmental, promyelination state, versus the injury response state.

Validation of differential expression was performed for several of the genes identified by this focused analysis of myelin and QKI genes as well as genes identified in the original, unbiased differential expression analysis that had highlighted an effect on immune response. As demonstrated in Figure $5 f$, fold changes measured by qPCR for day 1 versus control samples showed a strong correlation with fold changes measured by microarray analysis (Fig. 5-3 available at https://doi.org/10.1523/JNEUROSCI.2487-17.2018.f5-3, exact statistical output).

\section{Expression patterns of QKI isoforms in postnatal and} adult ANs

To extend our observation of QKI regulation in AN during postnatal development, we analyzed the expression of total QKI (pan) and the three different isoforms, focusing on the following three critical stages of myelination: P3, P7, and P14 (Fig. $6 a$ and Fig. 6-1 available at https://doi.org/10.1523/JNEUROSCI.2487-17.2018. f6-1, exact statistical output). Pan-QKI expression increased gradually through postnatal development, with a significant increase in expression between P3 and P14. All three of these transcripts were detectable throughout postnatal development, with QKI-7 being more abundant than QKI-5 and QKI-6. QKI-6 and QKI-7 were both significantly upregulated during postnatal development, while QKI-5 was significantly downregulated. These patterns match findings for QKI isoform expression in the mouse brain (Ebersole et al., 1996), with QKI-6 and QKI-7 increasing and QKI-5 decreasing in the mouse AN at times that coincide with the onset of myelination. 
We further examined auditory QKI expression, detecting total and variant $\mathrm{QKI}$ proteins in mouse and human cochlear sections. Analyses in mice were focused on RC (Fig. 6b), which contains satellite glial cells (SGCs) that ensheath soma of SGNs and Schwann cells (SCs) that myelinate fibers. Immunohistochemical analyses were performed on cochlear sections from 2-month-old young adult mice (Fig. $6 c, d, f$ ) and P14 mice (Fig. 6e), and both ears from a 38-year-old human donor (Fig. 6g). QKI-5 was expressed in nuclei of both SCs and SGCs (Fig. 6c). QKI-6 and QKI-7 were expressed predominantly in the cytoplasm of glia surrounding SGNs and fibers (Fig. 6d,e). Pan-QKI detection in the mouse confirmed that total QKI protein was distributed in both nucleus and cytoplasm but that it was limited to glial cells (Fig. 6f). Pan-QKI detection in human temporal bones revealed a similar distribution, with QKI present in nuclei and cytoplasm of SCs and SGCs, but not of neurons (Fig. $6 g$ ).

\section{Reduction of QKI protein expression in AN glial cells of adult $Q K I^{F L / F L ; P L P C r e E R T}$ mice}

To investigate the importance of QKI RBPs to glial cell function in the auditory system, we examined the effects of QKI deficiency by using the $Q K I^{F L / F L ; P L P C r e E R T}$ mouse model that targets all QKI variants in glial cells. The $Q K I^{F L / F L ; P L P C r E R T}$ mouse model was generated by crossing $Q K I^{F L / F L}$ with an inducible Cre knock-out line, $P L P$-CreERT, that induces QKI knockout in Plp1-expressing glial cells after being activated by injections of OHT (Doerflinger et al., 2003).

Immunostaining analyses of RC and OSL regions were performed on cochleae of 15-week-old OHT-treated QKI ${ }^{\text {FL/FL;PLPCreERT }}$ mice and compared with QKI ${ }^{\mathrm{FL} / \mathrm{FL} ;-}$ littermate controls (Fig. 7a). Immunostaining for Pan-QKI showed that nuclear QKI was notably reduced in SGC nuclei in QKI-deficient cochleae compared with glia in control cochlea (Fig. 7b). QKI was also substantially reduced in glial cytoplasm of $Q K I^{F L / F L ; P L P C r e E R T}$ mice compared with controls, which had a QKI distribution comparable to that seen in CBA/CaJ mice (Fig. $6 f$ ). Figure $7 c$ illustrates a substantial loss of QKI in nuclei and cytoplasm of SCs ensheathing peripheral fibers in the OSL. To determine QKI reduction specifically in the glial cells, dual immunostaining was performed for Pan-QKI with Sox10, a marker of glial cell nuclei (Britsch et al., 2001; Breuskin et al., 2010). We chose the prodifferentiation/myelination factor Sox10 because it is expressed in fully differentiated, mature SCs in the adult peripheral nervous system (Kuhlbrodt et al., 1998; Britsch et al., 2001; Finzsch et al., 2010). In control mice, QKI colocalized with Sox10 in nuclei of SGCs and SCs in RC (Fig. $7 d$ ). However, only a few $\mathrm{QK}^{+}$cells stained positively with Sox 10 antibody in QKI-deficient mice (Fig. 7d). Quantification of Sox $10^{+}$glia cells expressing QKI showed that there was a profound reduction in Pan-QKI ${ }^{+} / \mathrm{Sox}_{10}{ }^{+} / \mathrm{DAPI}^{+}$cell density in the OSL of QKI ${ }^{F L / F L}$; PLPCreERT mice compared with controls (Fig. 7e and Fig. 7-1 available at https://doi.org/10.1523/JNEUROSCI.2487-17.2018. f7-1, exact statistical output). Quantification of Pan- $-\mathrm{KI}^{+} /$ Sox $10^{+} / \mathrm{DAPI}^{+}$cells in RC also showed a significantly reduced density in QKI-deficient mice compared with controls (Fig. $7 f$ and Fig. 7-1 available at https://doi.org/10.1523/JNEUROSCI. 2487-17.2018.f7-1, exact statistical output). Total glia cell counts were not significantly different between $Q K I^{F L / F L ;-}$ and QKI ${ }^{F L / F L ; P L P C r e E R T}$ ANs.

To investigate further the consequences of QKI deficiency in cochlear glial cells, we evaluated the distribution of Sox2, a glial progenitor marker (Graham et al., 2003; Ferri et al., 2004), in control and QKI-deficient mice. Sox2 is a marker of immature, undifferentiated glia, and negatively regulates myelination by in- hibiting SC differentiation (Graham et al., 2003; Le et al., 2005) and promotes a progenitor-like glial state associated with neuronal repair after injury (Parrinello et al., 2010). Sox2 expression declines as glia mature (Le et al., 2005), but is present in satellite glial cells in adult nerves (Koike et al., 2015). In our studies, OSL of control mice contained only a few Sox ${ }^{+}$cells, and there was no colocalization of Sox2 with QKI in SCs (Fig. $7 g$ ). Sox $2^{+}$cells were more abundant in RC of control mice, and these Sox $2^{+}$ SGCs stained positively for Pan-QKI antibody (Fig. 7i). Interestingly, QKI-deficient mice showed a substantially different profile of Sox 2 expression. In the OSL, there was a notable increase in the number of Sox $2^{+}$SCs (Fig. $7 h$ ), although there was still no evident colocalization of Sox2 and residual QKI in the mutant animals. In RC of QKI-deficient mice, Sox $2^{+}$SGCs appeared to be increased compared with controls (Fig. 7j). These findings suggest that QKI deficiency may lead to dedifferentiation in a subset of cochlear glia.

\section{QKI deficiency results in demyelination and disruption of paranodal structures in the adult AN}

To examine further the role of QKI RBPs in AN architecture and function, we assessed the ultrastructure of myelin and flanking paranodes in $Q K I^{F L / F L ; P L P C r e E R T}$ mice in OSL, Hab), and RC regions (Fig. 8e). We examined 41 nodal structures associated with 54 glial cells of 3 QKI ${ }^{F L / F L ; P L P C r e E R T}$ mice and 17 nodal structures associated with 34 glial cells of 3 QKI $I^{F L / F L ;-}$ control mice. QKIdeficient mice showed evidence of hypomyelination, with a reduced number of lamellae wrapping some type I AN fibers (Fig. $8 a, f)$. Mutants also exhibited aberrant myelin structure and the presence of unmyelinated fibers (Fig. 8f). In addition, QKIdeficient mice exhibited pathologies in the paranodal region flanking the node of Ranvier. In the control mice, terminal myelin loops of each lamella were well organized, closely apposed to each other, and appeared to have proper septate-like junctions connecting the loop heads to the axolemma (Fig. 8b). In the QKI-deficient animals, the paranode had thinner terminal loop heads that were more broadly spaced, with some large gaps present within the structure (Fig. $8 g$ ). In the habenular region, where AN fibers form heminodes, demyelinate naturally, and connect to the organ of Corti, the control AN showed thickly myelinated fibers close to the bony perforation, along with unmyelinated heminodes (Fig. 8c). In contrast, in the QKI-deficient sample there were few myelinated fibers, which were in different states of dysmyelination, and there was a large open space clear of heminodes and axons (Fig. 8h). Soma of type I SGNs were densely myelinated and appeared healthy in control mice (Fig. $8 d$ ), whereas type I neurons in the QKI-deficient mice showed dysmyelination, with debris-laden spaces separating the cell membrane from the lamellae (Fig. 8i). Additionally, regions of hypomyelination with limited, noncompact lamellae could be seen in close proximity to densely myelinated soma (Fig. 8j). The observation of hypomyelination in the QKI-deficient animals was supported by a measured increase in the $\mathrm{G}$ ratio compared with controls (Fig. $8 k$ ).

To understand what may be causing the structural aberration in the axo-glial junctions at the paranodes in QKI-deficient animals, we performed coimmunostaining for contactin1 (Cntn1), an axo-glial connector protein (Boyle et al., 2001), and neurofilament 200 (Dillman et al., 2009). Sections from the OSL and RC in control samples showed characteristic paranodal patterns throughout the nerve fibers (Fig. $81, m$, top panels). Conversely, Cntnl staining and the distinctive patterns were largely absent in the QKI-deficient samples (Fig. 8l, $m$, bottom panels). As another measure of the effect of QKI deficiency on nodal structures, we 

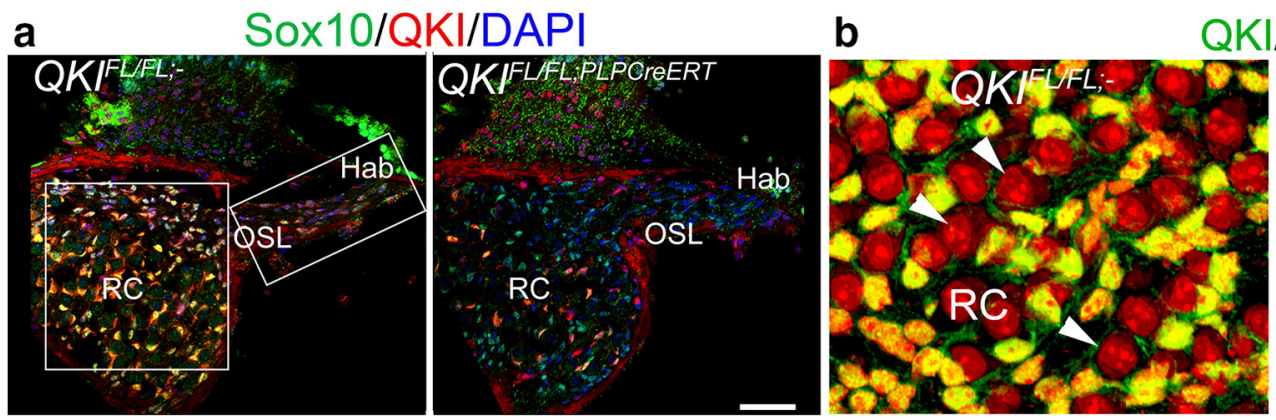

QKI/PI
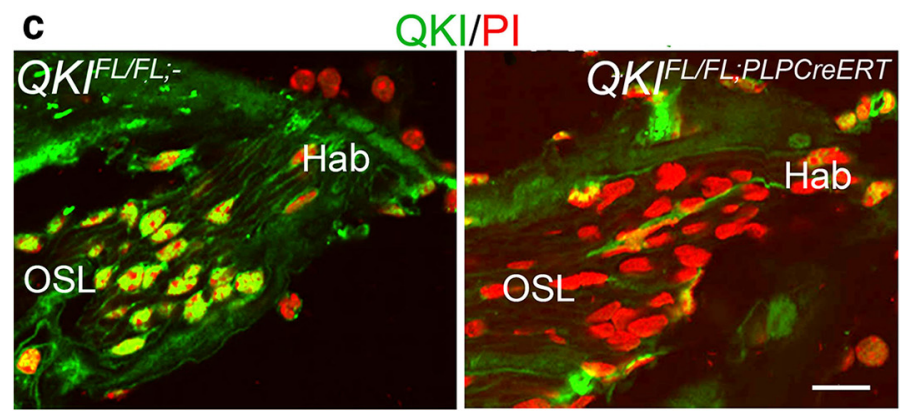

d

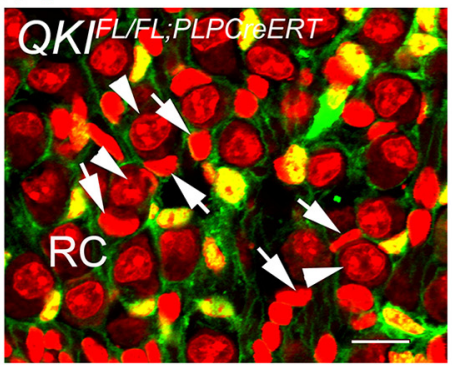

e
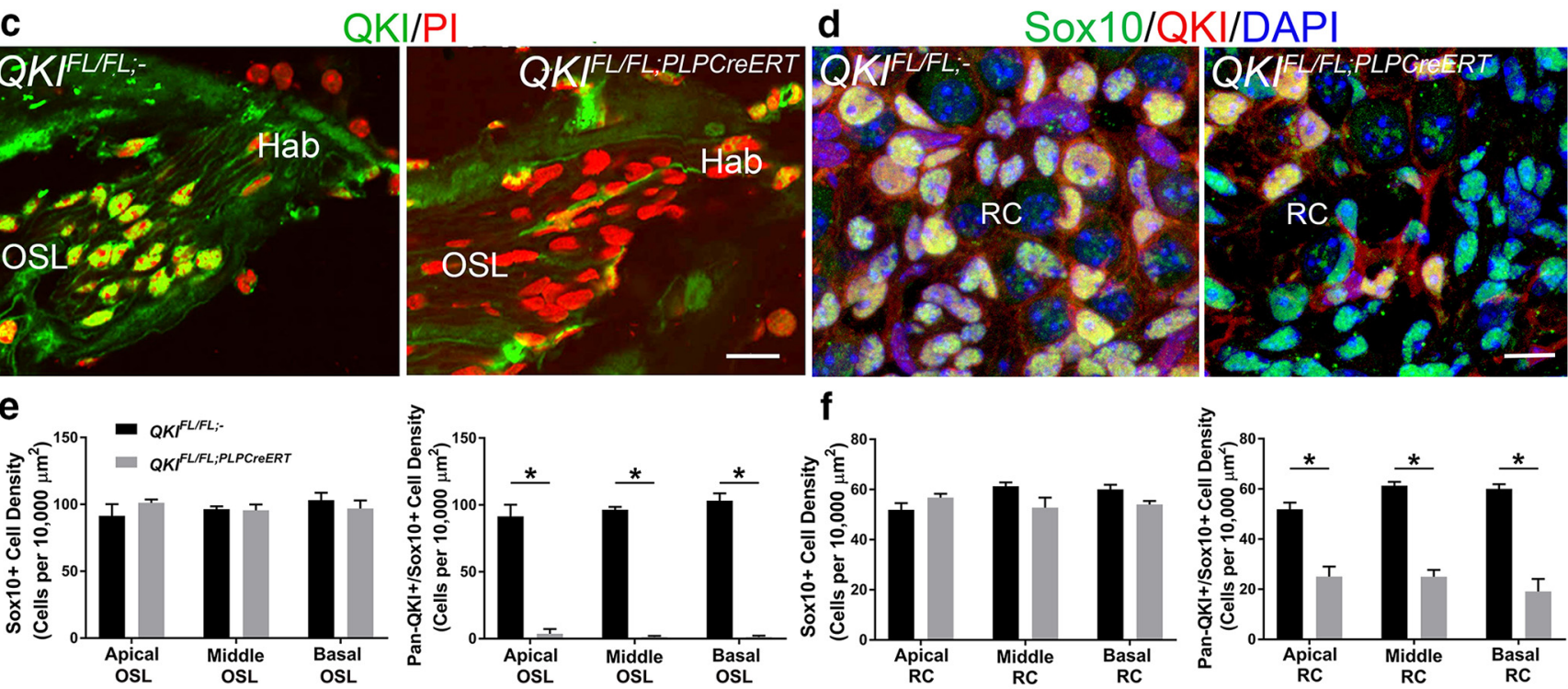

g Sox2/QKI/DAPI
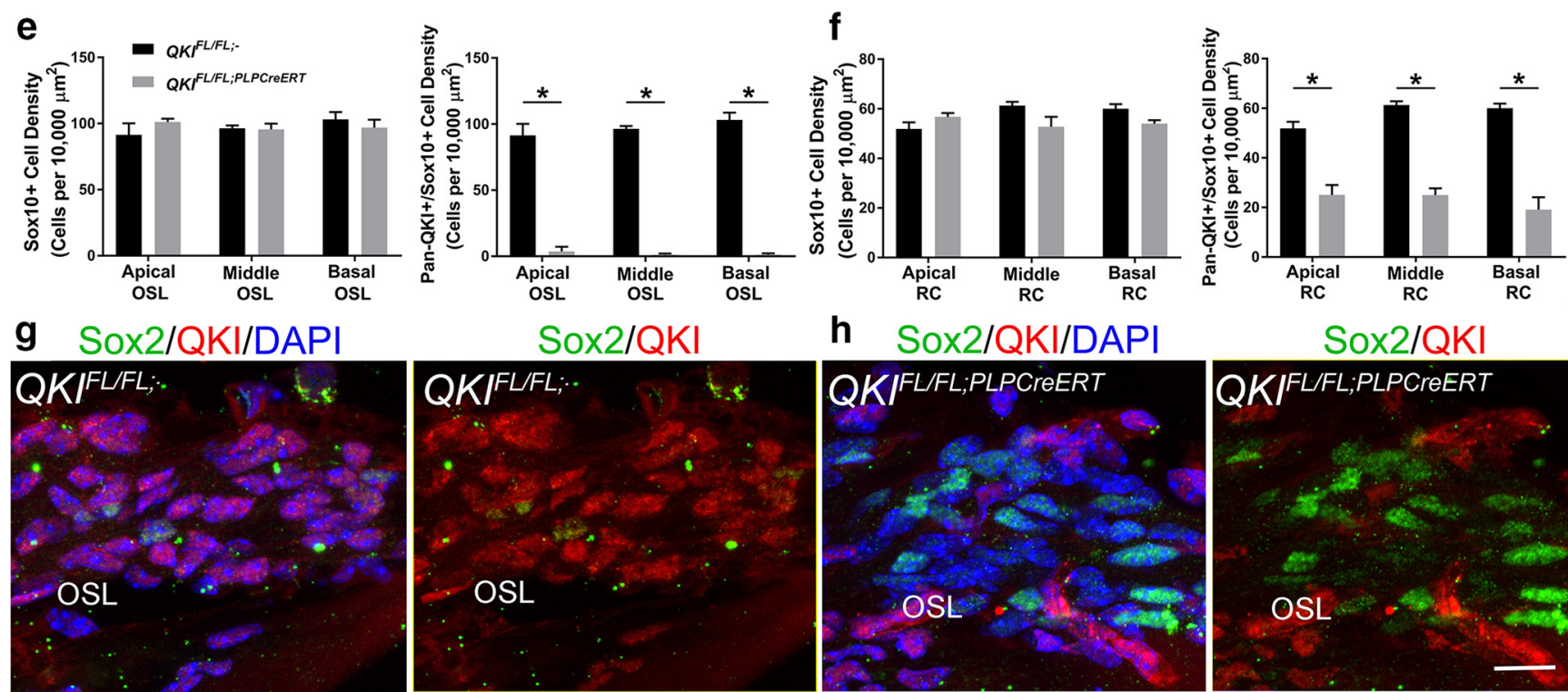

h SOX2/QKI/DAPI
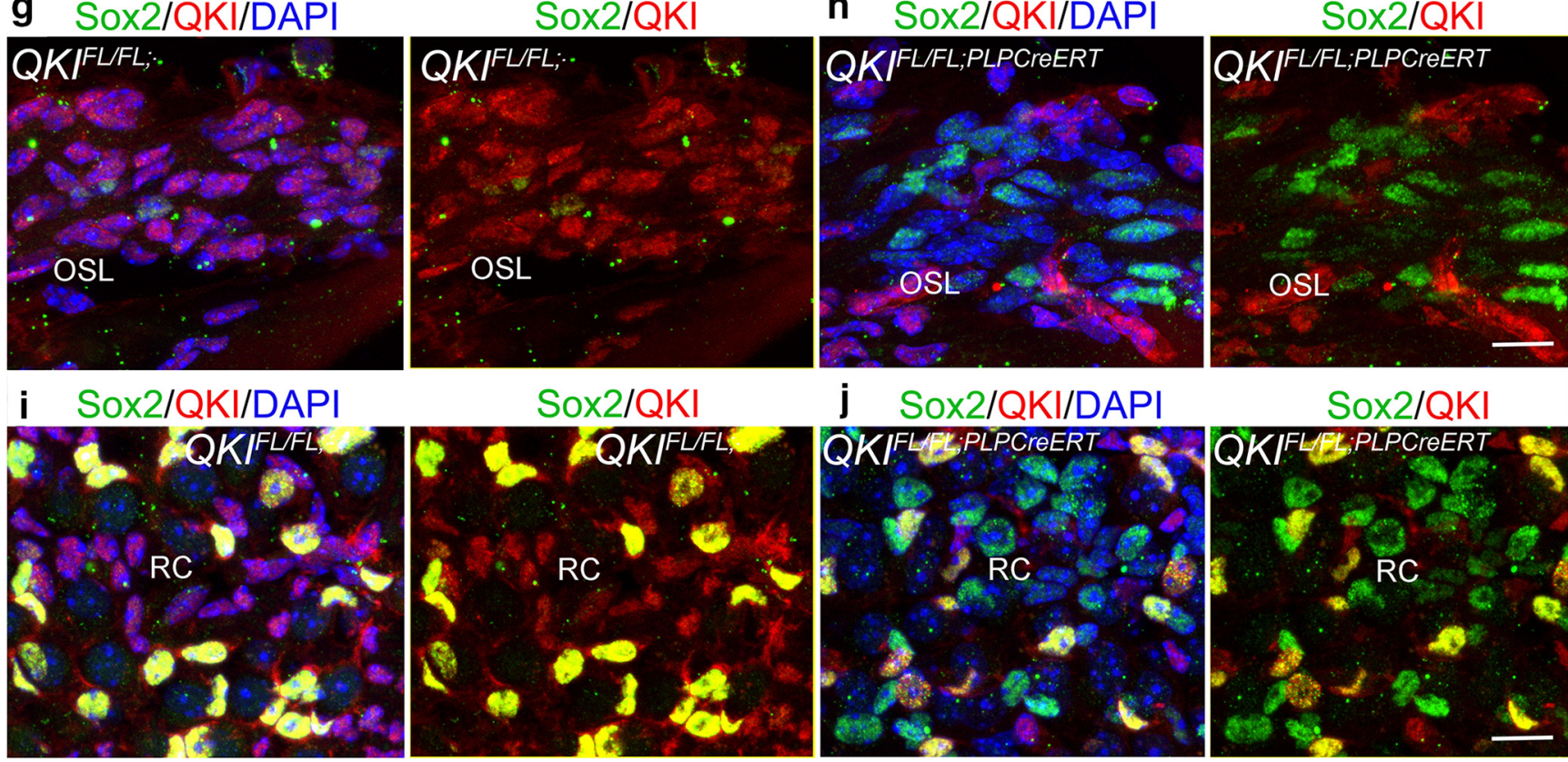

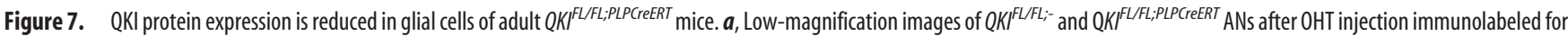
Pan-QKI and Sox10. RC, OSL, and Hab opening regions are indicated. Nuclei were counter stained with PI. $\boldsymbol{b}, \boldsymbol{c}$, Pan-QKI (QKI) immunoreactivity in glial cell nuclei is greatly reduced in both RC (b) and the OSL (c) of QKI exon 2 mutation mice. Control QKI $I^{F / F L /-}$ and mutant QKFI/FL;PLPCreERT mice were evaluated 4 weeks after OHT injections. $\boldsymbol{d}$, Dual immunolabeling for Pan-QKI and Sox10, demonstrates the loss of QKI expression in most Sox $10^{+}$glial cells (green). Nuclei were counterstained with DAPI. $\boldsymbol{e}, \boldsymbol{f}$, Cell density counts for total glial cells in 0SL (as indicated by Sox $10^{+}$cells)

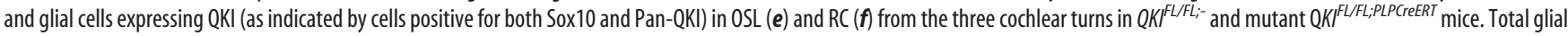
cells, based on density, were not significantly different between control and mutant mice in the OSL and RC of any of the turns (e, $\boldsymbol{f}$, left panels). There were almost no QKI-positive glial cells in the OSL (e, right); QKI-positive glial cell density in RC (f, right) was decreased by more than half in all cochlear turns in QKI-deficient mice compared with controls. $N=4$ for each group; error bars indicate SEM; ${ }^{*} p<0.05$ by the Mann-Whitney test (Figure 7-1 available at https://doi.org/10.1523/JNEUROSCI.2487-17.2018.f7-1, exact statistical output). $\boldsymbol{g}$-j, Dual immunostaining for Pan-0KI and

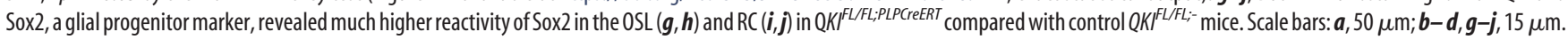




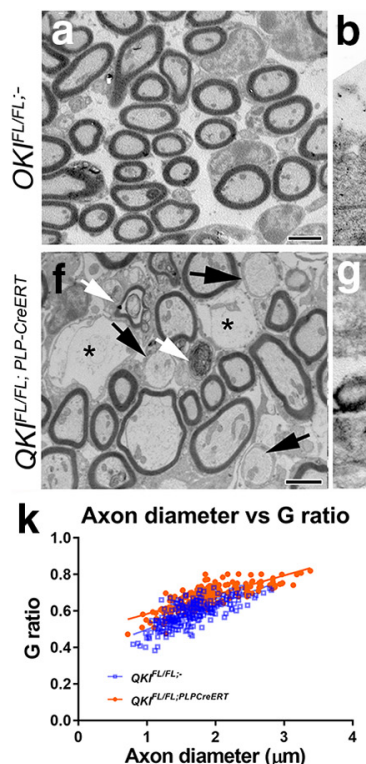

Myelin thickness vs $\mathrm{G}$ ratio
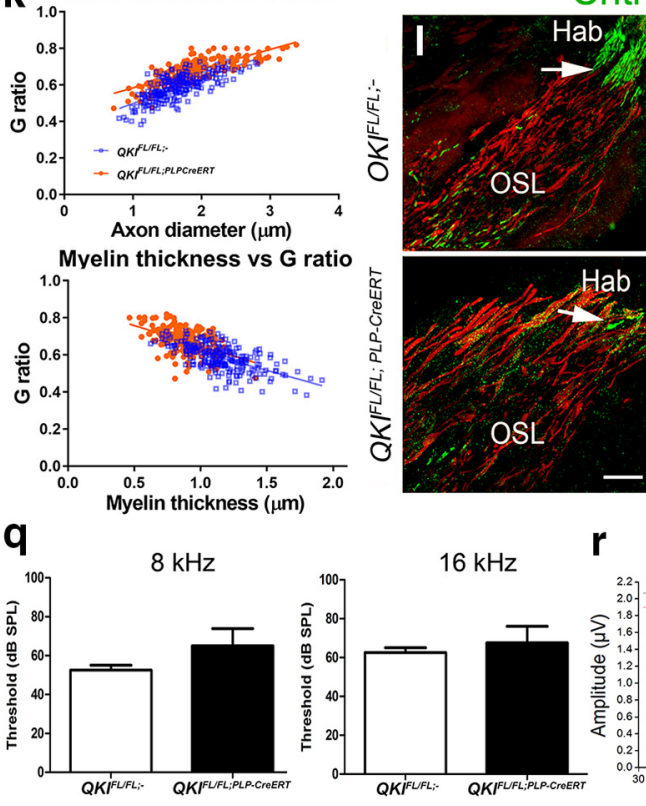

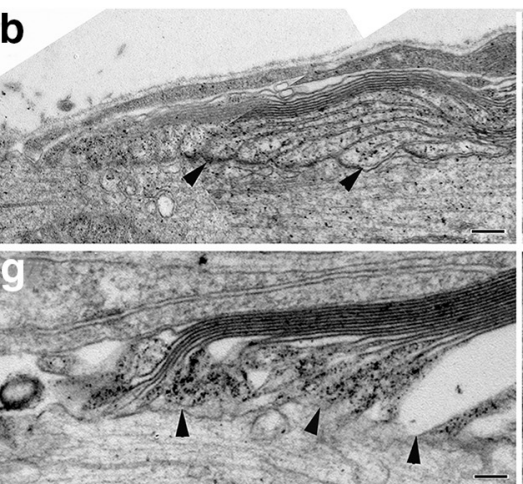

Cntn1/NF
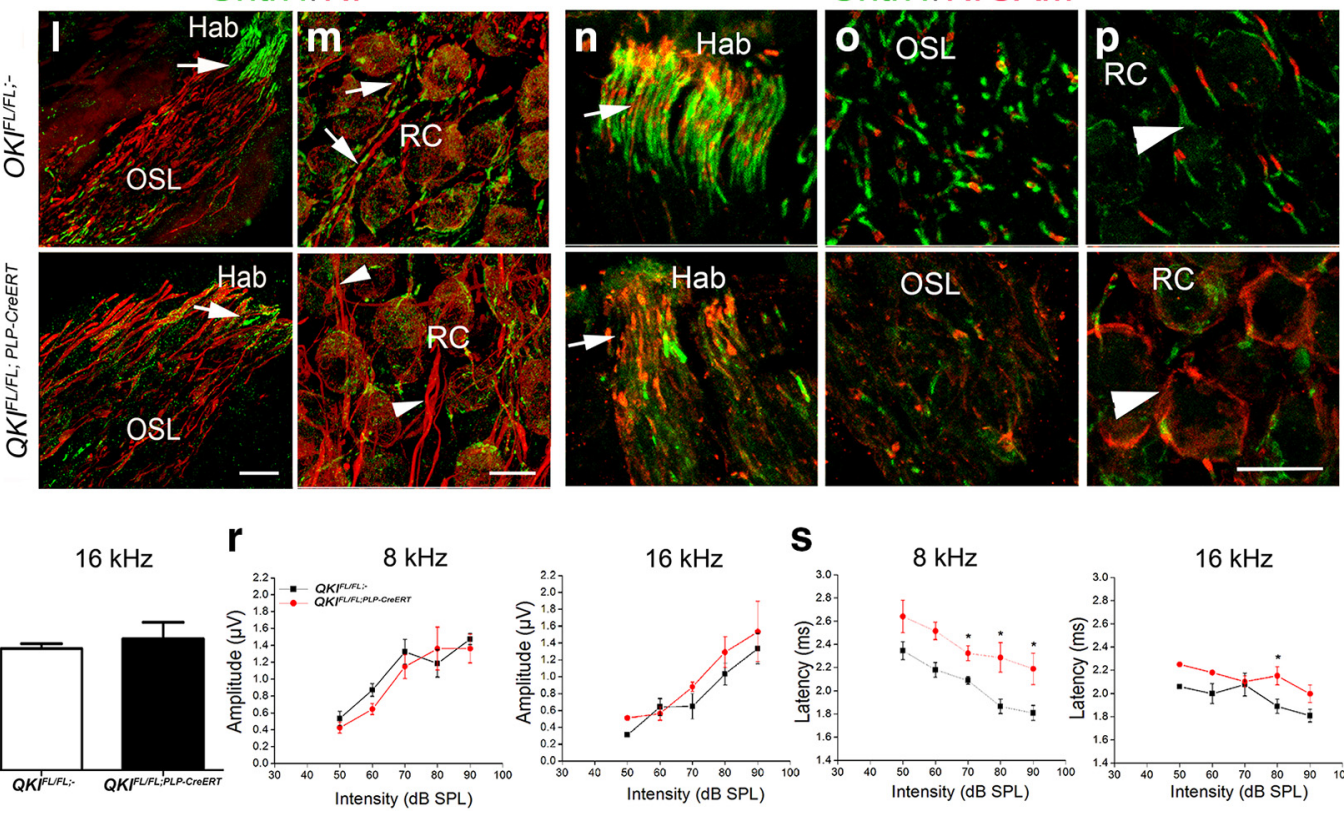

Figure 8. Diminished QKI expression results in demyelination and disruption of paranodal structures in the adult AN. $\boldsymbol{a}-\boldsymbol{d}$, Ultrastructural features of AN fibers ( $\boldsymbol{a})$, a paranodal junction ( $\boldsymbol{b})$, axon initial segments at the Hab opening (c), and SGNs in cochleae from control QKF FL/FL;- mice 4 weeks after OHT injections (d). e, Low-magnification image of a control AN highlighting the location of RC, OSL, and Hab. $\boldsymbol{f}$-j, Abnormalities in myelin morphology around axons and type I (I) SGNs and paranodal structures in QKI ${ }^{F L / F L}$; PLPCreERT mice 4 weeks after OHT injections. Pathological manifestations associated with diminished QKI expression included missing nerve fibers $\left(\boldsymbol{f} ;{ }^{*}\right)$, myelin enfolding $(\boldsymbol{f}$, white arrows), thinning myelin or reduced myelin lamellae $(\boldsymbol{f}, \boldsymbol{i}, \boldsymbol{j}$, black arrows), a loss of the myelin sheath at the axon initial segment $\left(\boldsymbol{h} ;{ }^{*}\right)$, and cytoplasmic vacuolization in glial cells ( $\boldsymbol{i}$, black arrowheads). The image in $\boldsymbol{g}$ shows disruptions in a paranode (black arrowheads) of a mutant mouse. Terminal myelin loops of the paranodal junctions flanking the nodes of Ranvier in the mutant mouse are disorganized, with abnormal spaces between the lamellae, and loop heads disconnected from the axolemma. Myelin lamellae ensheathing the soma of a mutant mouse are less compact and decreased in number ( $\boldsymbol{j}$, black arrow). $\boldsymbol{k}, \mathrm{G}$ ratio analysis revealed hypomyelination in the AN fibers, in particular the large-caliber fibers (with diameters of $>3 \mu \mathrm{m}$ ), in QKI ${ }^{F L F L}$;PLPCreERT mice. $I, \boldsymbol{m}$, Immunostaining for paranodal (ntn 1 and the neuronal marker neurofilament 200 showed that while numbers of NF ${ }^{+}$nerve fibers ( $\boldsymbol{m}$, white arrows) remained similar, the expression of paranodal $(n+n 1$ was decreased greatly (i, $\boldsymbol{m}$, white arrows) in mutant mice. $\boldsymbol{n}-\boldsymbol{p}$, Immunostaining for $\mathrm{Cntn} 1$ and the nodal marker NrCAM revealed the disappearance of (ntn $\boldsymbol{1}^{+}$paranodal flanks in heminodes at the Hab ( $\boldsymbol{n}$, white arrows) the nodes of Ranvier along fibers in the OSL (o), and in RC nodes ( $\boldsymbol{p}$; arrowheads). $\boldsymbol{q}, \boldsymbol{r}, \mathrm{ABR}$ measurements from control and mutant mice showed no significant difference in ABR wave I thresholds ( $\boldsymbol{q}$ ) or amplitudes ( $\boldsymbol{r}$ ) between the two groups at 8 and $16 \mathrm{kHz}$. s, In contrast, ABR wave I latencies were significantly increased in the mutant mice ( ${ }^{*} p<0.05$ by Student's unpaired $t$ test; Figure $8-1$ available at https://doi.org/10.1523/JNEUROSCI.2487-17.2018.f8-1, for exact statistical output). All data were presented as the mean \pm SEM. Scale bars: $\boldsymbol{a}, \boldsymbol{f}, 2 \mu \mathrm{m} ; \boldsymbol{b}, \boldsymbol{g}, 400 \mathrm{~nm} ; \boldsymbol{c}, \boldsymbol{d}, \boldsymbol{h}, \boldsymbol{i}, 2 \mu \mathrm{m}$; j, $800 \mathrm{~nm} ; \boldsymbol{I}, \boldsymbol{m}, 8 \mu \mathrm{m} ; \boldsymbol{p}$ (for $\boldsymbol{n}-\boldsymbol{p}), 8 \mu \mathrm{m}$.

performed dual immunostaining for NrCAM and Cntn1. In QKI-deficient animals, paranodes flanking the heminodes were devoid of Cntn1 at the habenula (Fig. $8 n$, bottom) and were mostly absent on the flanks of axonal nodes of Ranvier in the OSL compared with controls (Fig. 8o). Some Cntn $1^{+}$ paranodal structures were seen in the RC in QKI-deficient cochleae (Fig. 8p).

AN function was tested in QKI-deficient animals by ABR measurements. Comparison of controls with QKI-deficient animals showed that latencies of ABR wave I responses were significantly delayed for 8 and $16 \mathrm{kHz}$ stimuli in QKI-deficient animals (Fig. $8 s$ and Fig. 8-1 available at https://doi.org/10.1523/ JNEUROSCI.2487-17.2018.f8-1, exact statistical output). However,
ABR thresholds of wave I were not significantly different between control and QKI-deficient groups for 8 and $16 \mathrm{kHz}$ stimuli (Fig. 8q), and neither were the measured amplitudes (Fig. 8r). Together, these findings show that QKI-deficient mice have ABR defects consistent with the dysmyelination observed in these animals.

\section{Discussion}

While it is well established that myelination of nerve fibers by myelinating glia and dynamic regulation of this activity are crucial for proper nerve function, little is known about pathological changes in cochlear myelinating glia following injury/stress such as noise exposure. Our findings show that noise exposure sufficient for inducing nerve degeneration and permanent hearing 
loss elicits rapid cellular and molecular responses on myelinating glia. Our data reveal that dysfunction of QKI RBPs and their putative targets lead to myelinating glial dysfunction, resulting in SGN demyelination, disruption of paranodal axo-glial junctions, and AN functional deficiencies. These findings implicate a new mechanism of AN functional deficiency in noise-induced hearing loss (NIHL).

Exposure to moderate noise levels, for example octave-band noise at $<100 \mathrm{~dB}$ SPL for $2 \mathrm{~h}$ in $\mathrm{CBA} / \mathrm{CaJ}$ mice, can lead to temporary threshold shifts but chronic decreases in suprathreshold amplitudes. Such a response is characteristic of hair cell ribbon synaptopathy and has been termed "hidden hearing loss" (Liberman, 2015). However, pathological effects in moderatenoise models are relatively minor in the period shortly after noise exposure (Kujawa and Liberman, 2006). Here we used a model of NIHL with more severe noise exposure levels of 106 or $112 \mathrm{~dB}$ SPL for $2 \mathrm{~h}$ at $8-16 \mathrm{kHz}$. Within a short time, young adult mice showed permanent ABR threshold shifts across most cochlear frequency regions, synaptopathy, and a reduction in hair cell numbers. This exposure protocol generates a cochlear injury of sufficient magnitude to allow characterization of the cellular and molecular responses of the AN. In a previous study, a noise exposure regimen of $110 \mathrm{~dB}$ SPL for $9 \mathrm{~h}$ in adult rat ears resulted in demyelination of the central portion of the AN and decreased conduction velocity (Tagoe et al., 2014). Our data expand on this important finding, showing that such noise causes demyelination of the SGNs and paranodal axo-glial junctions in the peripheral process in the ANs. These results are also consistent with those of a previous report (Kurioka et al., 2016) in which thinner myelin sheaths were identified in the peripheral process of the AN after noise exposure.

Another interesting finding of our study is that inflammatory cells, particularly activated monocytes/macrophages but not granulocytes/neutrophils, are involved in demyelination of SGNs and ANs after noise exposure. Our data showed that the macrophages appear to be recruited to and activated in regions of noise-induced demyelination. This was supported by our gene expression analysis, which found inflammation to be one of the top biological processes induced in AN after noise exposure. After injury in the peripheral nervous system, degenerating myelin and axon debris is phagocytosed by either resident or infiltrating macrophages (Chen et al., 2015). Emerging evidence suggests that monocytes/macrophages can be both detrimental and beneficial with regard to nerve regeneration and remyelination (Miron and Franklin, 2014). Our recent study demonstrated that hematopoietic-derived monocytes/macrophages contribute to AN remodeling after SGN loss (Lang et al., 2016). Additionally, Kaur et al. (2015), reported that macrophage recruitment into the cochlea enhances the survival of SGNs in a model of selective hair cell deletion. Further experiments are needed to determine whether macrophages in the AN promote remyelination of AN and neuron survival.

Glial proliferation following injury is an important aspect of remyelination involved in nerve repair. In the peripheral nervous system, rapid Schwann cell proliferation is required for remyelination following injury (Ludwin, 1988). In the CNS, glia (e.g., oligodendrocytes) can proliferate after injury, but the period is more restricted than that of the SCs in the peripheral nervous system (Ludwin, 1988). Even under severe injury conditions that induce rapid type I SGN loss, glial cells show a dramatic increase in proliferation. However, despite this remarkable capacity of glial cells to proliferate in response to injury, there is no direct evidence of AN remyelination or axon regeneration after co- chlear injury for animal models of NIHL, despite several decades of study (Schmiedt, 1984; Spoendlin, 1985; Borg et al., 1995; Bohne and Harding, 2000; Liberman, 2016; Liberman and Kujawa, 2017). Here, our finding that QKI RBPs and associated myelin targets undergo dysregulation after noise exposure provides molecular insight into the failure of remyelination and regeneration after noise injury and is potentially applicable to forms of neurodegenerative disease (Dutta and Trapp, 2011).

RNA splicing is a key mechanism for generating proteomic diversity in neural cells, which require coordination of complex activities such as myelination, synaptogenesis, and nerve regeneration (Grabowski, 2011). RBPs, which bind to specific cisacting splicing elements on pre-mRNAs, play a vital role in regulating cell-specific and developmental stage-specific alternative splicing (Braunschweig et al., 2013). The QKI RBPs have all been shown to affect RNA splicing patterns in myelinating cells, thus influencing myelination. QKI-5 was found to regulate myelination by affecting pre-mRNA splicing of myelin genes (Wu et al., 2002). QKI-6, in coordination with heterologous nuclear ribonucleoproteins factors $\mathrm{A} 1$ and $\mathrm{H} / \mathrm{F}$, regulated splicing in myelinating cells of the CNS (Zhao et al., 2010; Mandler et al., 2014), and its forced expression in oligodendrocytes partially rescued hypomyelination and severe tremor in QKI-deficient mice (Zhao et al., 2006). Ectopic expression of QKI-6 and QKI-7 in myelinating glial cells blocked proliferation and promoted myelination of the peripheral nervous system (Larocque et al., 2009). Here, our transcriptomic data revealed distinct QKI isoform expression patterns in noise-exposed animals as well as during mouse hearing development. During development, the transition from immature to mature (myelinating) state was matched by an increase in QKI-6 and QKI-7 and a decrease in QKI-5. Interestingly, in noise-exposed ANs, while there were suggestive expression differences for all QKI isoforms, only an upregulation of QKI-7 was detected as being significant. Thus, the QKI isoform expression pattern following noise injury does not fully recapitulate a developmental, promyelination state. These data suggest the possibility that this deficiency in the QKI isoform response, and the downstream consequences on myelin target gene expression, are causal factors in the failure of remyelination leading to NIHL. A better understanding of how QKI isoform expression is controlled in cochlear glia may lead to new therapeutic interventions for NIHL and other neurodegenerative disorders.

In conclusion, our studies reveal the critical roles of myelinating glia and QKI RBPs in the maintenance of adult AN. In response to noise injury, adult mice rapidly exhibit glial dysfunction and altered expression of QKI RBPs in the AN. Transcriptomic analysis and pathophysiological evaluation of noise-exposed mice indicate that these dysfunctions represent a primary response to noise injury that ultimately culminates in NIHL. Furthermore, our data suggest that the influence of QKI on myelination is dependent on precise control of QKI isoform expression.

\section{References}

Akil O, Sun Y, Vijayakumar S, Zhang W, Ku T, Lee CK, Jones S, Grabowsk GA, Lustig LR (2015) Spiral ganglion degeneration and hearing loss as a consequence of satellite cell death in saposin B-deficient mice. J Neurosci 35:3263-3275. CrossRef Medline

Allen DL, Bandstra ER, Harrison BC, Thorng S, Stodieck LS, Kostenuik PJ, Morony S, Lacey DL, Hammond TG, Leinwand LL, Argraves WS, Bateman TA, Barth JL (2009) Effects of spaceflight on murine skeletal muscle gene expression. J Appl Physiol 106:582-595. CrossRef Medline

Amor V, Feinberg K, Eshed-Eisenbach Y, Vainshtein A, Frechter S, Grumet M, Rosenbluth J, Peles E (2014) Long-term maintenance of $\mathrm{Na}^{+}$channels at nodes of Ranvier depends on glial contact mediated by gliomedin and NrCAM. J Neurosci 34:5089-5098. CrossRef Medline 
Bao J, Ohlemiller KK (2010) Age-related loss of spiral ganglion neurons. Hear Res 264:93-97. CrossRef Medline

Bohne BA, Harding GW (2000) Degeneration in the cochlea after noise damage: primary versus secondary events. Am J Otol 21:505-509. Medline

Borg E, Canlon B, Engström B (1995) Noise-induced hearing loss. literature review and experiments in rabbits. Morphological and electrophysiological features, exposure parameters and temporal factors, variability and interactions. Scand Audiol Suppl 40:1-147. Medline

Boyle ME, Berglund EO, Murai KK, Weber L, Peles E, Ranscht B (2001) Contactin orchestrates assembly of the septate-like junctions at the paranode in myelinated peripheral nerve. Neuron 30:385-397. CrossRef Medline

Braunschweig U, Gueroussov S, Plocik AM, Graveley BR, Blencowe BJ (2013) Dynamic integration of splicing within gene regulatory pathways. Cell 152:1252-1269. CrossRef Medline

Breuskin I, Bodson M, Thelen N, Thiry M, Borgs L, Nguyen L, Stolt C, Wegner M, Lefebvre PP, Malgrange B (2010) Glial but not neuronal development in the cochleo-vestibular ganglion requires Sox10. J Neurochem 114:1827-1839. CrossRef Medline

Britsch S, Goerich DE, Riethmacher D, Peirano RI, Rossner M, Nave KA, Birchmeier C, Wegner M (2001) The transcription factor Sox10 is a key regulator of peripheral glial development. Genes Dev 15:66-78. CrossRef Medline

Champely S (2017) Package pwr. Vienna, Austria: R Foundation.

Chen P, Piao X, Bonaldo P (2015) Role of macrophages in wallerian degeneration and axonal regeneration after peripheral nerve injury. Acta Neuropathol 130:605-618. CrossRef Medline

Cooley MA, Harikrishnan K, Oppel JA, Miler SF, Barth JL, Haycraft CJ, Reddy SV, Scott Argraves W (2014) Fibulin-1 is required for bone formation and bmp-2-mediated induction of osterix. Bone 69:30-38. CrossRef Medline

Daley JM, Thomay AA, Connolly MD, Reichner JS, Albina JE (2008) Use of Ly6G-specific monoclonal antibody to deplete neutrophils in mice. J Leukoc Biol 83:64-70. CrossRef Medline

Darbelli L, Richard S (2016) Emerging functions of the quaking RNAbinding proteins and link to human diseases. Wiley Interdiscip Rev RNA 7:399-412. CrossRef Medline

Darbelli L, Vogel G, Almazan G, Richard S (2016) Quaking regulates neurofascin 155 expression for myelin and axoglial junction maintenance. J Neurosci 36:4106-4120.April CrossRef Medline

de Oliveira S, Rosowski EE, Huttenlocher A (2016) Neutrophil migration in infection and wound repair: going forward in reverse. Nat Rev Immunol 16:378-391. CrossRef Medline

Dillman RO, Selvan SR, Schiltz PM, McClay EF, Barth NM, DePriest C, de Leon C, Mayorga C, Cornforth AN, Allen K (2009) Phase II trial of dendritic cells loaded with antigens from self-renewing, proliferating autologous tumor cells as patient-specific antitumor vaccines in patients with metastatic melanoma: final report. Cancer Biother Radiopharm 24: 311-319. CrossRef Medline

Doerflinger NH, Macklin WB, Popko B (2003) Inducible site-specific recombination in myelinating cells. Genesis 35:63-72. CrossRef Medline

Dutta R, Trapp BD (2011) Mechanisms of neuronal dysfunction and degeneration in multiple sclerosis. Prog Neurobiol 93:1-12. CrossRef Medline

Ebersole TA, Chen Q, Justice MJ, Artzt K (1996) The quaking gene product necessary in embryogenesis and myelination combines features of RNA binding and signal transduction proteins. Nat Genet 12:260-265. CrossRef Medline

El-Badry MM, Ding DL, McFadden SL, Eddins AC (2007) Physiological effects of auditory nerve myelinopathy in chinchillas. Eur J Neurosci 25: 1437-1446. CrossRef Medline

Ferri A, Cavallaro M, Braida D, Di Cristofano A, Canta A, Vezzani A, Ottolenghi S, Pandolfi PP, Sala M, DeBiasi S, Nicolis SK (2004) Sox2 deficiency causes neurodegeneration and impaired neurogenesis in the adult mouse brain. Development 131:3805-3819. CrossRef Medline

Finzsch M, Schreiner S, Kichko T, Reeh P, Tamm ER, Bösl MR, Meijer D, Wegner M (2010) Sox10 is required for schwann cell identity and progression beyond the immature schwann cell stage. J Cell Biol 189:701712. CrossRef Medline

Fu XD, Ares M Jr (2014) Context-dependent control of alternative splicing by RNA-binding proteins. Nat Rev Genet 15:689-701. CrossRef Medline

Galarneau A, Richard S (2005) Target RNA motif and target mRNAs of the quaking STAR protein. Nat Struct Mol Biol 12:691-698. CrossRef Medline

Grabowski P (2011) Alternative splicing takes shape during neuronal development. Curr Opin Genet Dev 21:388-394. CrossRef Medline
Graham V, Khudyakov J, Ellis P, Pevny L (2003) SOX2 functions to maintain neural progenitor identity. Neuron 39:749-765. CrossRef Medline

Hao X, Xing Y, Moore MW, Zhang J, Han D, Schulte BA, Dubno JR, Lang H (2014) Sox10 expressing cells in the lateral wall of the aged mouse and human cochlea. PLoS One 9:e97389. CrossRef Medline

Hardy RJ, Loushin CL, Friedrich VL Jr, Chen Q, Ebersole TA, Lazzarini RA, Artzt K (1996) Neural cell type-specific expression of QKI proteins is altered in quakingviable mutant mice. J Neurosci 16:7941-7949. Medline

Hirose K, Discolo CM, Keasler JR, Ransohoff R (2005) Mononuclear phagocytes migrate into the murine cochlea after acoustic trauma. J Comp Neurol 489:180-194. CrossRef Medline

Hossain WA, Antic SD, Yang Y, Rasband MN, Morest DK (2005) Where is the spike generator of the cochlear nerve? Voltage-gated sodium channels in the mouse cochlea. J Neurosci 25:6857-6868. CrossRef Medline

Huang da W, Sherman BT, Lempicki RA (2009a) Systematic and integrative analysis of large gene lists using DAVID bioinformatics resources. Nat Protoc 4:44-57. CrossRef Medline

Huang da W, Sherman BT, Lempicki RA (2009b) Bioinformatics enrichment tools: paths toward the comprehensive functional analysis of large gene lists. Nucleic Acids Res 37:1-13. CrossRef Medline

Irizarry RA, Hobbs B, Collin F, Beazer-Barclay YD, Antonellis KJ, Scherf U, Speed TP (2003) Exploration, normalization, and summaries of high density oligonucleotide array probe level data. Biostatistics 4:249-264. CrossRef Medline

Jyothi V, Li M, Kilpatrick LA, Smythe N, LaRue AC, Zhou D, Schulte BA, Schmiedt RA, Lang H (2010) Unmyelinated auditory type i spiral ganglion neurons in congenic Ly5.1 mice. J Comp Neurol 518:3254-3271. CrossRef Medline

Kaur T, Zamani D, Tong L, Rubel EW, Ohlemiller KK, Hirose K, Warchol ME (2015) Fractalkine signaling regulates macrophage recruitment into the cochlea and promotes the survival of spiral ganglion neurons after selective hair cell lesion. J Neurosci 35:15050-15061. CrossRef Medline

Khimich D, Nouvian R, Pujol RR, Tom Dieck S, Egner A, Gundelfinger ED, Moser T, Noublan R, Pujol RR, tom Dieck S, Egner A, Gundelfinger ED, Moser T (2005) Hair cell synaptic ribbons are essential for synchronous auditory signalling. Nature 434:889-894. CrossRef Medline

Kim KX, Rutherford MA (2016) Maturation of $\mathrm{NaV}$ and KV channel topographies in the auditory nerve spike initiator before and after developmental onset of hearing function. J Neurosci 36:2111-2118. CrossRef Medline

Koike T, Wakabayashi T, Mori T, Hirahara Y, Yamada H (2015) Sox2 promotes survival of satellite glial cells in vitro. Biochem Biophys Res Commun 464:269-274. CrossRef Medline

Ku YC, Renaud NA, Veile RA, Helms C, Voelker CC, Warchol ME, Lovett M (2014) The transcriptome of utricle hair cell regeneration in the avian inner ear. J Neurosci 34:3523-3535. CrossRef Medline

Kuhlbrodt K, Herbarth B, Sock E, Hermans-Borgmeyer I, Wegner M (1998) Sox10, a novel transcriptional modulator in glial cells. J Neurosci 18:237250. Medline

Kujawa SG, Liberman MC (2006) Acceleration of age-related hearing loss by early noise exposure: evidence of a misspent youth. J Neurosci 26: 2115-2123. CrossRef Medline

Kurioka T, Lee MY, Heeringa AN, Beyer LA, Swiderski DL, Kanicki AC, Kabara LL, Dolan DF, Shore SE, Raphael Y (2016) Selective hair cell ablation and noise exposure lead to different patterns of changes in the cochlea and the cochlear nucleus. Neuroscience 332:242-257. CrossRef Medline

Lang H, Schulte BA, Zhou D, Smythe N, Spicer SS, Schmiedt RA (2006) Nuclear factor $\kappa \mathrm{B}$ deficiency is associated with auditory nerve degeneration and increased noise-induced hearing loss. J Neurosci 26:3541-3550. CrossRef Medline

Lang H, Xing Y, Brown LN, Samuvel DJ, Panganiban CH, Havens LT, Balasubramanian S, Wegner M, Krug EL, Barth JL (2015) Neural stem/progenitor cell properties of glial cells in the adult mouse auditory nerve. Sci Rep 5:13383. CrossRef Medline

Lang H, Nishimoto E, Xing Y, Brown LN, Noble KV, Barth JL, LaRue AC, Ando K, Schulte BA (2016) Contributions of mouse and human hematopoietic cells to remodeling of the adult auditory nerve after neuron loss. Mol Ther 24:2000-2011. CrossRef Medline

Larocque D, Fragoso G, Huang J, Mushynski WE, Loignon M, Richard S, Almazan G (2009) The QKI-6 and QKI-7 RNA binding proteins block proliferation and promote Schwann cell myelination. PLoS One 4:e5867. CrossRef Medline 
Le N, Nagarajan R, Wang JY, Araki T, Schmidt RE, Milbrandt J (2005) Analysis of congenital hypomyelinating Egr2Lo/Lo nerves identifies Sox 2 as an inhibitor of schwann cell differentiation and myelination. Proc Natl Acad Sci U S A 102:2596-2601. CrossRef Medline

Li C, Wong WH (2001) Model-based analysis of oligonucleotide arrays: expression index computation and outlier detection. Proc Natl Acad Sci U S A 98:31-36. CrossRef Medline

Liberman MC (2015) Hidden hearing loss. Sci Am 313:48-53.

Liberman MC (2016) Noise-induced hearing loss: permanent versus temporary threshold shifts and the effects of hair cell versus neuronal degeneration. Adv Exp Med Biol 875:1-7. CrossRef Medline

Liberman MC, Kiang NY (1978) Acoustic trauma in cats. Cochlear pathology and auditory-nerve activity. Acta Otolaryngol Suppl 358:1-63. Medline

Liberman MC, Kujawa SG (2017) Cochlear synaptopathy in acquired sensorineural hearing loss: manifestations and mechanisms. Hear Res 349: 138-147. CrossRef Medline

Liu W, Saint DA (2002) Validation of a quantitative method for real time PCR kinetics. Biochem Biophys Res Commun 294:347-353. CrossRef Medline

Long P, Corfas G (2014) Dynamic regulation of myelination in health and disease. JAMA Psychiatry 71:1296-1297. CrossRef Medline

Ludwin SK (1988) Remyelination in the central nervous system and the peripheral nervous system. Adv Neurol 47:215-254. Medline

Mandler MD, Ku L, Feng Y (2014) A cytoplasmic quaking I isoform regulates the hnRNP F/H-dependent alternative splicing pathway in myelinating glia. Nucleic Acids Res 42:7319-7329. CrossRef Medline

Miron VE, Franklin RJ (2014) Macrophages and CNS remyelination. J Neurochem 130:165-171. CrossRef Medline

Nakamura R, Nishimura T, Ochiai T, Nakada S, Nagatani M, Ogasawara H (2013) Availability of a microglia and macrophage marker, Iba-1, for differential diagnosis of spontaneous malignant reticuloses from astrocytomas in rats. J Toxicol Pathol 26:55-60. CrossRef Medline

Parrinello S, Napoli I, Ribeiro S, Wingfield Digby P, Fedorova M, Parkinson DB, Doddrell RD, Nakayama M, Adams RH, Lloyd AC (2010) EphB sgnaling directs peripheral nerve regeneration through Sox2-dependent schwann cell sorting. Cell 143:145-155. CrossRef Medline

Pilotte J, Larocque D, Richard S (2001) Nuclear translocation controlled by alternatively spliced isoforms inactivates the QUAKING apoptotic inducer. Genes Dev 15:845-858. CrossRef Medline

Rao SN, Pearse DD (2016) Regulating axonal responses to injury: the intersection between signaling pathways involved in axon myelination and the inhibition of axon regeneration. Front Mol Neurosci 9:33. CrossRef Medline

Sautter NB, Shick EH, Ransohoff RM, Charo IF, Hirose K (2006) CC chemokine receptor 2 is protective against noise-induced hair cell death: studies in CX3CR1+/GFP mice. J Assoc Res Otolaryngol 7:361-372. CrossRef Medline

Schindelin J, Arganda-Carreras I, Frise E, Kaynig V, Longair M, Pietzsch T, Preibisch S, Rueden C, Saalfeld S, Schmid B, Tinevez JY, White DJ,
Hartenstein V, Eliceiri K, Tomancak P, Cardona A (2012) Fiji: an opensource platform for biological-image analysis. Nat Methods 9:676-682. CrossRef Medline

Schmiedt RA (1984) Acoustic injury and the physiology of hearing. J Acoust Soc Am 76:1293-1317. CrossRef Medline

Spoendlin H (1984) Factors inducing retrograde degeneration of the cochlear nerve. Ann Otol Rhinol Laryngol Suppl 112:76-82. Medline

Spoendlin H (1985) Histopathology of noise deafness. J Otolaryngol 14: 282-286. Medline

Supek F, Bošnjak M, Škunca N, Šmuc T (2011) REVIGO summarizes and visualizes long lists of gene ontology terms. PLoS One 6:e21800. CrossRef Medline

Susuki K (2013) Node of Ranvier disruption as a cause of neurological diseases. ASN Neuro 5:209-219. CrossRef Medline

Tagoe T, Barker M, Jones A, Allcock N, Hamann M (2014) Auditory nerve perinodal dysmyelination in noise-induced hearing loss. J Neurosci 34: 2684-2688. CrossRef Medline

Thakurela S, Garding A, Jung RB, Müller C, Goebbels S, White R, Werner HB, Tiwari VK (2016) The transcriptome of mouse central nervous system myelin. Sci Rep 6:25828. CrossRef Medline

Wan G, Corfas G (2017) Transient auditory nerve demyelination as a new mechanism for hidden hearing loss. Nat Commun 8:14487. CrossRef Medline

Wu JI, Reed RB, Grabowski PJ, Artzt K (2002) Function of quaking in myelination: regulation of alternative splicing. Proc Natl Acad Sci U S A 99:4233-4238. CrossRef Medline

Xing Y, Samuvel DJ, Stevens SM, Dubno JR, Schulte BA, Lang H (2012) Age-related changes of myelin basic protein in mouse and human auditory nerve. PLoS One 7:e34500. CrossRef Medline

Zhang Y, Chen K, Sloan SA, Bennett ML, Scholze AR, O'Keeffe S, Phatnani HP, Guarnieri P, Caneda C, Ruderisch N, Deng S, Liddelow SA, Zhang C, Daneman R, Maniatis T, Barres BA, Wu JQ (2014) An RNA-sequencing transcriptome and splicing database of glia, neurons, and vascular cells of the cerebral cortex. J Neurosci 34:11929-11947. CrossRef Medline

Zhao L, Tian D, Xia M, Macklin WB, Feng Y (2006) Rescuing qkV dysmyelination by a single isoform of the selective RNA-binding protein QKI J Neurosci 26:11278-11286. CrossRef Medline

Zhao L, Mandler MD, Yi H, Feng Y (2010) Quaking I controls a unique cytoplasmic pathway that regulates alternative splicing of myelin-associated glycoprotein. Proc Natl Acad Sci U S A 107:19061-19066. CrossRef Medline

Zhao S, Fernald RD (2005) Comprehensive algorithm for quantitative realtime polymerase chain reaction. J Comput Biol 12:1047-1064. CrossRef Medline

Zhou R, Abbas PJ, Assouline JG (1995) Electrically evoked auditory brainstem response in peripherally myelin-deficient mice. Hear Res 88:98-106. CrossRef Medline

Zimmermann CE, Burgess BJ, Nadol JB Jr (1995) Patterns of degeneration in the human cochlear nerve. Hear Res 90:192-201. CrossRef Medline 